\title{
A study on surface morphology and tension in laser powder bed fusion of Ti-6Al-4V
}

\author{
Mahyar Khorasani ${ }^{1,2}$ (D) $\cdot$ AmirHossein Ghasemi $^{3} \cdot$ Umar Shafique Awan $^{1} \cdot$ Elahe Hadavi $^{2} \cdot$ Martin Leary $^{4}$. \\ Milan Brandt ${ }^{4} \cdot$ Guy Littlefair ${ }^{5}$. William $\mathrm{O}^{\prime} \mathrm{Neil}^{6} \cdot$ Ian Gibson ${ }^{1,2}$
}

Received: 8 May 2020 / Accepted: 5 October 2020 / Published online: 4 November 2020

(C) The Author(s) 2020

\begin{abstract}
When reporting surface quality, the roughest surface is a reference for the measurements. In LPBF due to recoil pressure and scan movement, asymmetric surface is shaped, and surface roughness has different values in different measurement orientations. In this research, the influence of the laser powder bed fusion (LPBF) process parameters on surface tension and roughness of Ti$6 \mathrm{AI}-4 \mathrm{~V}$ parts in three orientations are investigated. To improve the mechanical properties, heat treatment was carried out and added to the designed matrix to generate a comprehensive data set. Taguchi design of experiment was employed to print 25 samples with five process parameters and post-processing. The effect and interaction of the parameters on the formation of surface profile comprising tension, morphology and roughness in various directions have been analysed. The main contribution of this paper is developing a model to approximate the melting pool temperature and surface tension based on the process parameters. Other contributions are an analysis of process parameters to determine the formation and variation of surface tension and roughness and explain the governing mechanisms through rheological phenomena. Results showed that the main driving factors in the variation of surface tension and formation of the surface profile are thermophysical properties of the feedstock, rheology and the temperature of the melting pool. Also, the results showed that while the value of surface tension is the same for each test case, morphology and the value of roughness are different when analysing the surface in perpendicular, parallel and angled directions to laser movement.
\end{abstract}

Keywords Additive manufacturing $\cdot$ Selective laser melting $\cdot$ Surface morphology $\cdot$ Surface roughness $\cdot$ Porosity

Mahyar Khorasani

a.khorasani@deakin.edu.au

AmirHossein Ghasemi

amir_hosein_ghasemi2012@yahoo.com

Umar Shafique Awan

u.awan@deakin.edu.au

Elahe Hadavi

e.hadavi@utwente.nl

Martin Leary

martin.leary@rmit.edu.au

Milan Brandt

milan.brandt@ rmit.edu.au

Guy Littlefair

guy.littlefair@aut.ac.nz

William O'Neil

wo207@cam.edu.au
Ian Gibson

i.gibson@utwente.nl

1 School of Engineering, Deakin University, Waurn Ponds, Victoria, Australia

2 Fraunhofer Project Centre for Complex System Engineering, Department of Design, Production and Management, University of Twente, Enschede, The Netherlands

3 Faculty of Engineering, University of Kashan, Ravandi Bolivar, Kashan, Iran

4 School of Engineering, RMIT University, Victoria, Australia

5 Faculty of Design and Creative Technologies, Auckland University of Technology, Auckland, New Zealand

6 Institute for Manufacturing, University of Cambridge, Cambridge, UK 


\section{Nomenclature}

$B_{\mathrm{A}}$
$C$

\section{Coefficient matrix}

$C_{\mathrm{ps}} \quad$ Specific heat capacity in solid state

$C_{\mathrm{pm}} \quad$ Specific heat capacity in liquid state

$E_{\mathrm{d}} \quad$ Energy density

E Error

$H \quad$ Cross product matrix

$H_{\mathrm{s}} \quad$ Hatch space

$L_{\mathrm{p}} \quad$ Laser power

$L_{\mathrm{T}} \quad$ Layer thickness

$L M \quad$ Level of matrix

$P_{0} \quad$ Reference value for pressure

$P_{\mathrm{ch}} \quad$ Chamber pressure

$P_{\text {recoil }} \quad$ Recoil pressure

$Q \quad$ Internal heat

$P \quad$ Droplet pressure

$R_{\text {cur }} \quad$ Curvature radius

$R_{\mathrm{g}} \quad$ Universal gas constant

$S \quad$ Spreading parameter

$S_{\mathrm{s}} \quad$ Scan speed

$T_{0} \quad$ Reference value for temperature

$T_{\mathrm{c}} \quad$ Critical temperature

$T_{1} \quad$ Liquid temperature

$T_{\mathrm{s}} \quad$ Solidus temperature

$T_{\mathrm{mp}} \quad$ Titanium melting point temperature

$T_{\mathrm{v}} \quad$ Vapour temperature

$U_{\mathrm{fb}} \quad$ Speed of melted particles at the

bottom of melting pool

$W_{\text {su }} \quad$ Other works

$\gamma_{S L}, \gamma_{S G}, \gamma_{L G} \quad$ Surface tension for solid-liquid, solid-gas and liquid-gas

$\gamma_{0} \quad$ Constant surface tension for

each liquid

$\Delta H_{\text {phase change }}$ Phase change (microstructural)

enthalpy for solid state

$\Delta H_{\mathrm{m}} \quad$ Enthalpy phase change for solid to liquid

$\eta \quad$ Absorption coefficient

$\lambda \quad$ Wave length

$\rho \quad$ Density

\section{Introduction}

Laser powder bed fusion (LPBF) is an additive manufacturing (AM) method for the process of metal alloys by fusing and melting the metallic powder with a laser beam $[1,2]$. Among different metallic alloys which have been used in LPBF, Ti$6 \mathrm{Al}-4 \mathrm{~V}$ has gained much attention due to its wide range of applications in the industry [3,4]. Titanium alloys are often used for bio-implantation because of their high strength, low density, corrosion resistance and relatively low Young's modulus. Delfs et al. [5] showed that the surface roughness and porosity of LPBF-fabricated parts are determined by the dimensions, stability and behaviour of the melt pool. However, surface roughness created by the fusion of metallic powder suffers from other problems such as balling and staircase effect.

Chen et al. [6] showed that the surface roughness of Ti6Al-4V manufactured by LPBF is also dependent on the sample's location on the build platform and powder size distribution. The surfaces that are closer to the laser origin are rougher than those that are further away. The hatch distance is another important factor reported by Sanaei et al. [7] that can influence the geometric characteristics of cracks and surface morphology. Yadroitsev et al. [8] reported that to reduce surface roughness, the maximum hatch space should not exceed the average width of continuous tracks. They also reported that for onepass thin wall fabrication by LPBF (fixed laser power), layer thickness and scanning speed play important roles. Khorasani et al. [9] modeled the average surface using artificial neural networks by feeding process and post-process parameters. This research showed that heat treatment in beta phase and laser power had the highest influence on the value of average surface.

In addition to the in-process parameters, the post-process parameters, including heat treatment, machining, stressrelieving and hot isostatic pressing (HIP), influence the surface quality of the LPBF-manufactured parts. To modify the surface properties, various thermochemical treatments are applied by Vayssette et al. [10] on LPBF-fabricated parts, which can result in the formation of titanium oxide layers on the surface and change the surface morphology and roughness.

Moreover, the half-molten particles from the powder increase surface roughness by creating the protuberances on the surface with the spherical shape [11]. The deficiencies of the inclined surfaces, which are fabricated by the LPBF process, are split into down-skin (below over-hang area) and upskin (above over-hang area). Perez et al. [12] showed that the geometry of step edges and the amount of half-melted particles from step edges determines the up-skin surface roughness. Gusarov et al. [13] reported that in down-skin surface roughness, the limited contact between the surface of powder particles and the insulating air gap between particles results in the limited local heat dissipation from fusion zone of the powder bed.

Some researchers formulated a mathematical model for predicting surface roughness at various sloping angles. This model particularly considers the presence of particles on the upper surface along with a staircase effect. Unlike the straightforward staircase model, this model is responsible for observed roughness over a full surface angle that was found by Strano et al. [14]. Investigation on surface treatment for the optimisation of LPBF Ti-6Al-4V porous structures described that chemical etching solutions increased the effectiveness of 
surface treatment excessively. However, Pyka et al. [15] showed that surface treatment was also affected by the combination of different process factors, i.e. surface treatment duration and hydrofluoric (HF) acid concentration. Surface profile in LPBF is asymmetric due to recoil pressure and scan movement, and there is no literature explaining the governing mechanisms for these phenomena.

This paper is complementary to the previous research on the effect of process parameters on the average surface. In this experiment, Taguchi design of experiment (DOE) was selected to model five parameters, including four process parameters and a post-process, to explain their effect on the value of surface tension and surface profile including morphology and roughness in different directions to laser movement. The effect of each parameter on the results as well as the interaction of each two factors on various surface profiles has been plotted, analysed and discussed. All related phenomena are explained based on rheology and melting pool-related phenomena.

\section{Experimental setup}

\subsection{Powder material and LPBF operation}

Samples were printed based on ASTM E8 and E8M using an LPBF 125HL (SLM Solutions GmbH, Lubeck, Germany), equipped with YLR-Fibre-Laser. The layer thickness was selected $30 \mu \mathrm{m}$ for all test samples, and the operational beam focus diameter was $100 \mu \mathrm{m}$.

\subsection{Design of experiment}

In the case of using full factorial DOE, the number of samples, time taken and, subsequently, the cost of the experiments sharply increase for expensive experiments such as in AM processes. Therefore, to reduce the cost and time of the experiment without affecting the accuracy of results, Taguchi L25 DOE was selected to examine five parameters on five levels. The parameters are laser power, scan speed, hatch spacing, laser pattern angle and heat treatment temperature. Factors in each column have to be analysed independently, and therefore the number of replications in each column is balanced. In this case, the design is stated as orthogonal. Table 1 shows the process parameters and their levels. We selected laser power, scan speed and hatch space, which play a role in energy density and temperature. Also, heat treatment was selected because this process is essential in improving mechanical properties [16, 17]. We also selected a laser scanning pattern angle to analyse the effect of the layering angle on the roughness. Based on original equipment manufacturer (OEM), the values of standard process parameters were selected. Then, considering the capability of the LPBF machine, the maximum and minimum ranges of parameters were chosen.

\subsection{Post-processing (heat treatment)}

In AM, more specifically when the process includes melting operation, the periodic cooling and heating during the build processes result in large thermal gradients and thermal residual stress history. To improve the ductility and machinability of the parts, different annealing processes followed by furnace cooling have been employed $[18,19]$. Table 1 shows the heat treatment conditions. In this instance, the heating and resident times were fixed at $120 \mathrm{~min}$, meaning the initial heating gradient steadily increased from room to the set temperature from 4.8 to $8.6{ }^{\circ} \mathrm{C} / \mathrm{min}$. The cooling rate was fixed at $5{ }^{\circ} \mathrm{C} / \mathrm{min}$ across all samples to prevent a detrimental impact on the mechanical properties due to the cooling rate on the samples. Due to the high cooling rate, as-built LPBF prototypes have comparatively high tensile strength and low ductility. To improve the mechanical properties and machinability of the parts, different annealing processes have been suggested [20]. These include stress relief annealing at $600^{\circ} \mathrm{C}$, mill annealing at 750 ${ }^{\circ} \mathrm{C}, \alpha+\beta$ annealing and $\beta$ annealing at $1050{ }^{\circ} \mathrm{C}$ followed by furnace cooling according to the related standards [21].

\subsection{Surface profilometry}

An optical profilometer (Alicona Infinite Focus) equipped with $\times 5$ to $\times 100$ operational lenses was used to scan the surface of the samples. For each direction, 10 different areas of the surface (parallel, angled and perpendicular) were selected for scanning of the LPBF-fabricated parts with a minimum range of $10 \mathrm{~mm}$ (for measurement length). The normalised value of surface parameters was calculated according to ISO 4288 and ISO 11056, and a high pass built-in Gaussian filter was applied. The lateral and vertical resolutions of the profilometer were $10 \mathrm{~nm}$ and $400 \mathrm{~nm}$. Based on the proposed DOE, 25 test samples with five repetitions were produced (totally 125 samples). Then, 30 profilometries were performed on each sample; thus, 3750 profiles were obtained, and the roughness for three directions was measured, so a total of 11,250 measurements were carried out. Subsequently, the average roughness of each sample was reported. The scanned area for surface profilometry was selected randomly in different parts of the components according to Fig. 1a. Subsequently, based on the obtained profilometry, images of various roughness including parallel, perpendicular and angled to scan movement were measured (Fig. 1b).

\section{Results}

\subsection{Taguchi analyses of obtained results}

To verify the performance of the Taguchi results, the mean values versus signal to noise $(\mathrm{S} / \mathrm{N})$ ratio was calculated. Signal 
Table 1 Experimental process parameters and levels (20 means no heat treatment)

\begin{tabular}{|c|c|c|c|c|c|c|c|}
\hline $\begin{array}{l}\text { Laser } \\
\text { power }(W)\end{array}$ & $\begin{array}{l}\text { Scan speed } \\
(\mathrm{mm} / \mathrm{min})\end{array}$ & $\begin{array}{l}\text { Hatch } \\
\text { spacing }(\mu \mathrm{m})\end{array}$ & $\begin{array}{l}\text { Scanning pattern } \\
\text { incrementing angle }\left(^{\circ}\right)\end{array}$ & $\begin{array}{l}\text { Heat treatment } \\
\text { Temperature }{ }^{\circ} \mathrm{C}\end{array}$ & $\begin{array}{l}\text { Heating } \\
\text { time (min) }\end{array}$ & $\begin{array}{l}\text { Resident } \\
\text { time (min) }\end{array}$ & $\begin{array}{l}\text { Cooling } \\
\text { time (min) }\end{array}$ \\
\hline 90 & 600 & 65 & 36 & 20 & - & - & - \\
\hline 95 & 650 & 70 & 40 & 600 & 120 & 120 & 120 \\
\hline 100 & 700 & 75 & 45 & 750 & 120 & 120 & 150 \\
\hline 105 & 750 & 80 & 60 & 925 & 120 & 120 & 185 \\
\hline 110 & 800 & 85 & 75 & 1050 & 120 & 120 & 210 \\
\hline
\end{tabular}

to noise is a sign of accuracy in each experiment. The surface quality for application of the LPBF-fabricated parts plays an important role. Therefore, in this analysis, the criterion of "smaller-is-better" was selected. To analysis the validity of each test, SNR versus mean effect plot for all directions (parallel, angled and perpendicular) were drawn. In this analysis, the more horizontal curves, the less influence on the outputs [22]. Also, the lowest values in the mean effect plot should stay exactly at the highest points in the SNR diagrams. As can be seen in Fig. 2, this occurred for almost all of the points, which shows the correctness of the experimental procedure. Figure 2 shows the "main effect" and SN plots.

\subsection{A predictive model for inputs versus outputs and correlations}

The artificial intelligence (AI)-based methods have higher accuracy than other statistical methods such as Poisson regression; however, AI methods cannot provide information on the interaction of factors. Therefore, to analyse the interaction

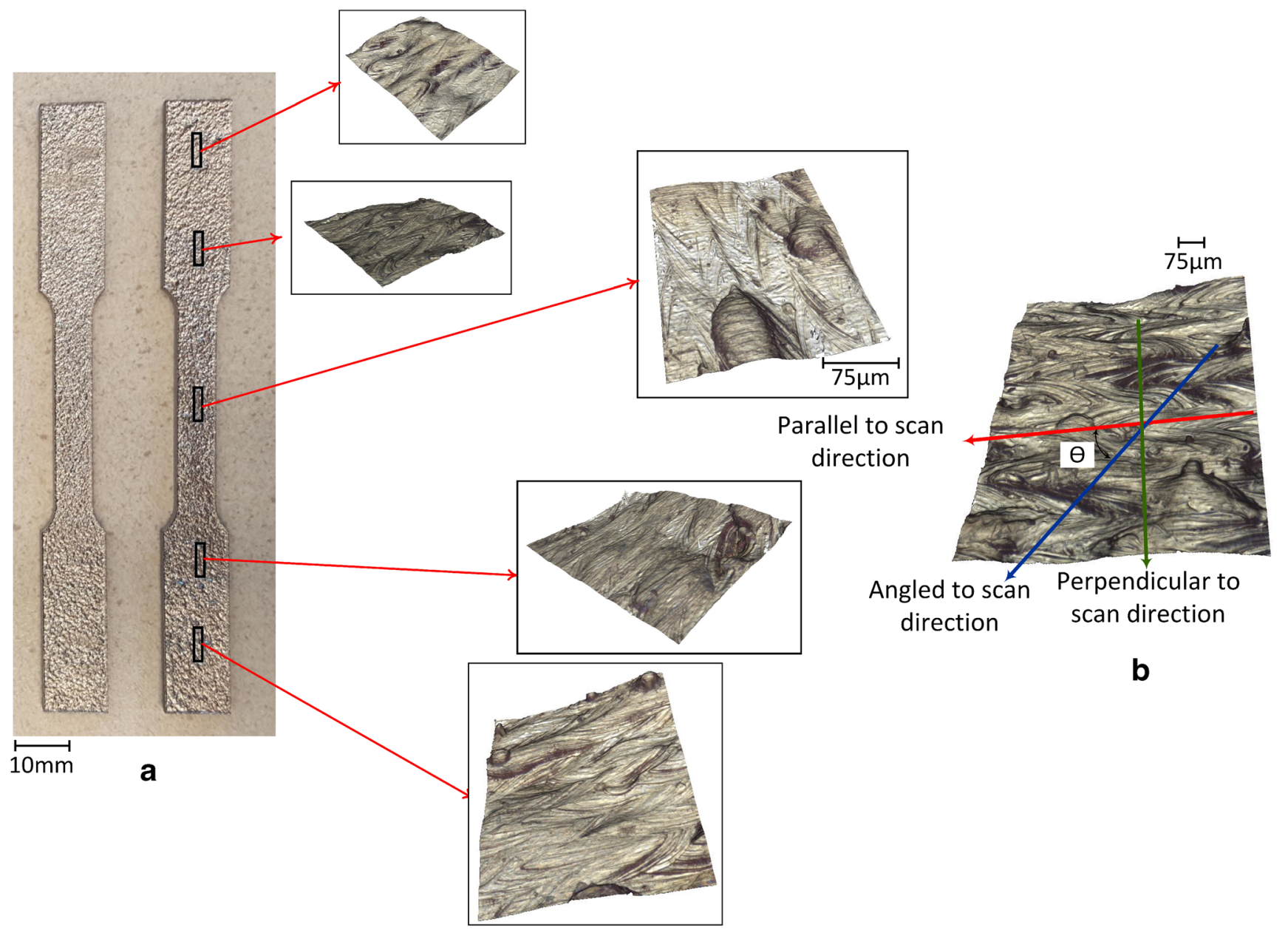

Fig. 1 (a) Surface roughness measurement from different parts of the samples. (b) Measurement directions 
Main Effects Plot for SN ratios For Ra Parallel

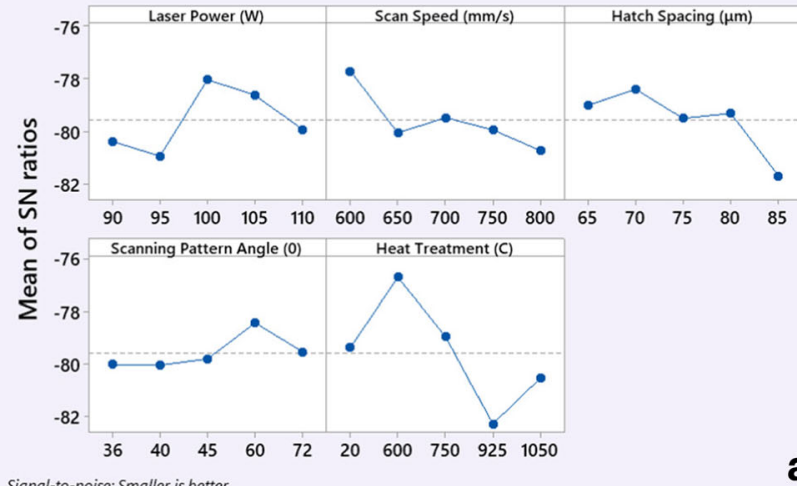

Main Effects Plot for SN ratios Ra Angled

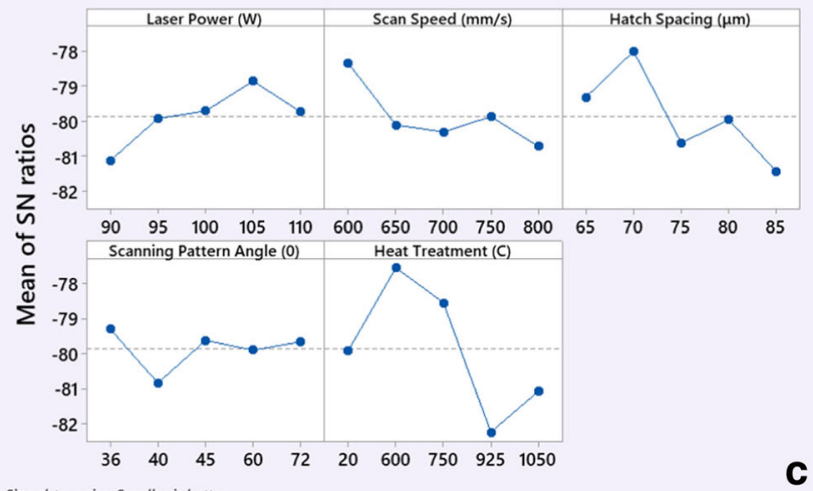

Signal-to-noise: Smaller is better

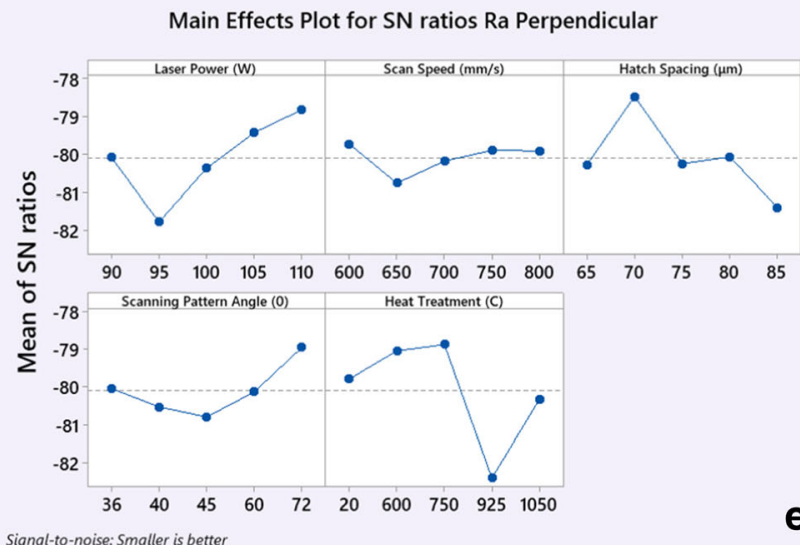

e

Fig. 2 Signal to noise and mean analysis diagrams in this research, statistical regression was used to model and explain the behaviour of the process. The general equation was calculated using a categorical predictor based on single interactions through the order. The link function was selected as logarithmic with a $95 \%$ confidence level for all intervals. The selected type of confidence intervals was two sided. Figure 3 shows the values from experimental results versus the prediction of the proposed Poisson model, demonstrating a very good correlation, and the accuracy of the proposed model is approved. The regression model was
Main Effects Plot for Means for Ra Parallel

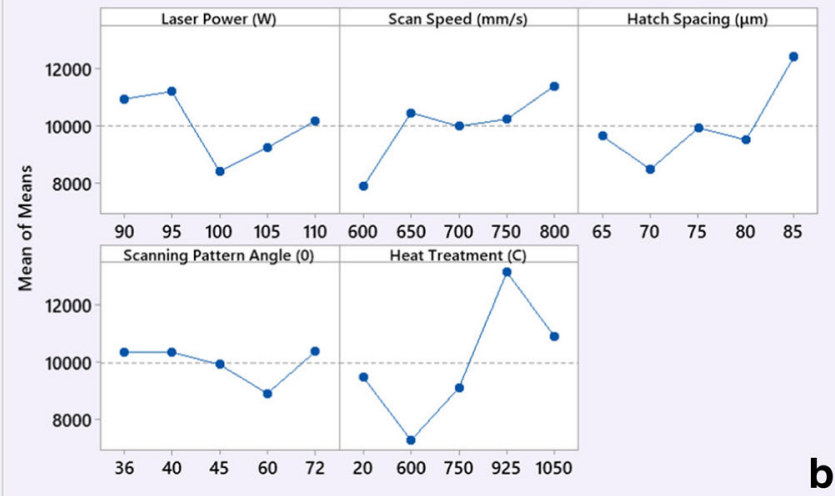

Main Effects Plot for Means Ra Angled

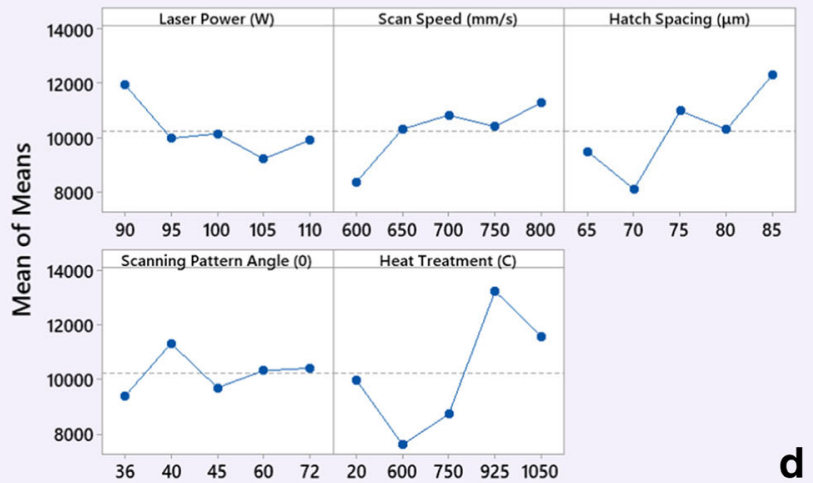

Main Effects Plot for Means Ra Perpendicular

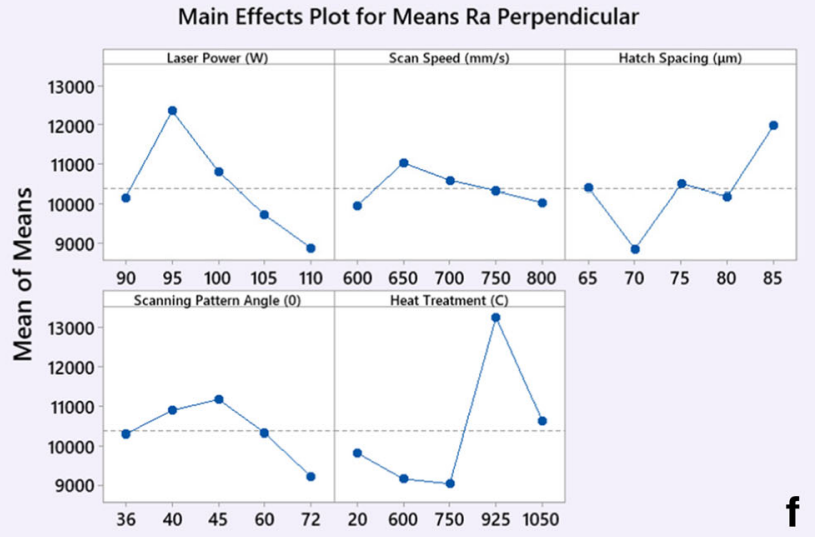

calculated based on outputs and the exponential function of categorical input data.

This model is summarised based on the following matrix:

Predict Value $=\exp \left(c+\left\{[L M]_{[1 \times 25]} \times[C M]_{[25 \times 1]}\right\}\right)$

$C$ is a constant value that is added to balance the equation, "coefficient matrix" contains the coefficient related to each 

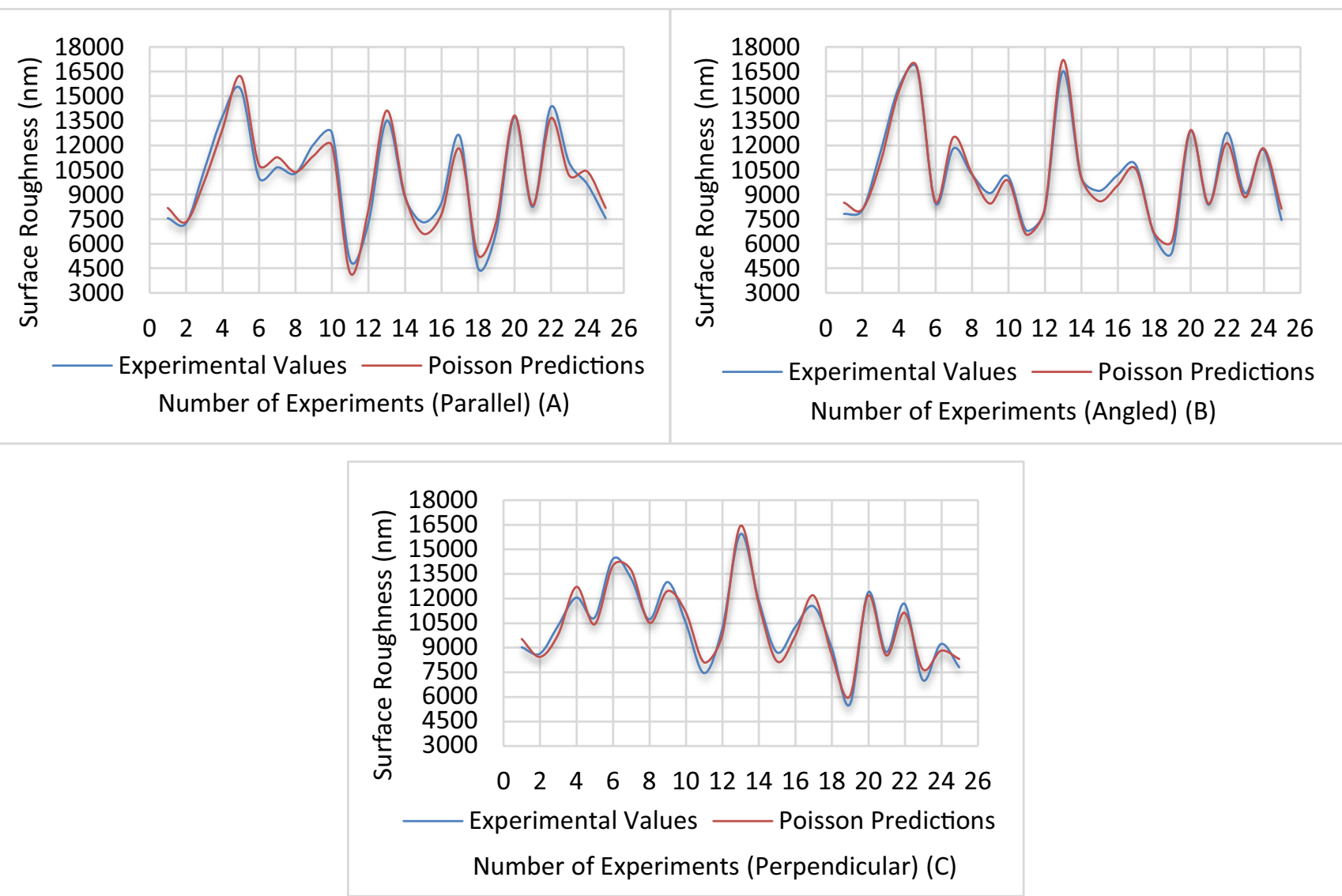

Fig. 3 Experimental measurement versus Poisson regression predictions

parameter, and "level matrix" is the matrix that determines the condition for prediction. This matrix has 25 arrays comprising five separate submatrices. Submatrices include laser power, scan speed, hatch space, scanning pattern angle and heat treatment. Each submatrix has an array of ([5*1]), and one of the arrays is 1 , and others are zero. The index of the array equal to 1 corresponds to the setup that is predicted.

The array value related to the matrix level is determined by DOE levels.
For example, to predict the $R_{\text {a }}$ parallel value related to setup with laser power $95(\mathrm{~W})$, scan speed $700 \mathrm{~mm} / \mathrm{s}$, hatch spacing $80 \mu \mathrm{m}$, scanning pattern angle $45^{\circ}$ and heat and treatment temperature $600{ }^{\circ} \mathrm{C}$, the level of matrix is determined as follows:

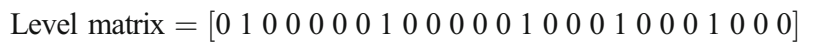

Therefore, constant value and coefficient matrix are:

$C=9.0118$

$$
\begin{aligned}
\text { Coefficient matrix = } & {\left[\begin{array}{lllllllllll}
0 & 0.06598 & -0.2953 & -0.18298 & -0.04563 & 0 & 0.29947 & 0.23439 & 0.28641 & 0.35921 & 0 \\
& -0.09703 & 0.00978 & 0.01731 & 0.27853 & 0 & -0.01004 & -0.02901 & -0.17999 & -0.080070 & -0.30167 \\
& -0.034280 .338540 .126
\end{array}\right] T }
\end{aligned}
$$

To predict the value related to each setup, it is necessary to rewrite matrix levels and recalculate it.

This procedure is acceptable for all models $\left(R_{\mathrm{a}}\right.$ in each direction).

The correlation factor is a factor that helps to validate the coverage of the proposed model on experimental data. Table 2
Table 2 Correlation factor for regression models

\begin{tabular}{ll}
\hline Direction & Correlation factor (categorical model) \\
\hline Parallel & $94.72 \%$ \\
Angled & $95.43 \%$ \\
Perpendicular & $97.45 \%$ \\
\hline
\end{tabular}


shows the correlation factor related to each model for categorical prediction:

The proposed model is dimensionless; in order to count units of input variables, another regression model could be used that is presented as follows:

$$
\begin{aligned}
\text { predicted value }= & C \times\left(L P^{P_{1}}\right) \times\left(S S^{P_{2}}\right) \times\left(H S^{P_{3}}\right) \\
& \times\left(S P^{P_{4}}\right) \times\left(H T^{P_{5}}\right)
\end{aligned}
$$

$C$ balances the equation and unit of output. This model also could carry the interaction between input parameters.

Another advantage of continuous models over the categorical model is an open range for input value between the lower and upper boundary of the experiment parameters. However, the fluctuations in the coefficient of correlation in this regression are higher than categorical regression. Therefore, in this research, categorical regression was used to analyse the data.

\subsection{Analysing the effective parameters using Taguchi and MANOVA}

\subsubsection{General multivariate analysis of variance}

In this section, multivariate analysis of variance (MANOVA) has been applied to the obtained data to show the effectiveness of each parameter. In order to do this, three important criteria comprising Hotelling-Lawley, Pillai's trace and Wilk's Lambda were utilised.

One of the most practical criteria for finding the effective parameters in ANOVA is Hotelling-Lawley. Based on this criterion, the trace of the cross-product matrix $(\mathrm{H})$ times by error sums of the square (E) can reject or accept a null hypothesis.

$T^{2}=\operatorname{Trace}\left(H E^{-1}\right)$

If $H$ is large compared with $\mathrm{E}$, then the Hotelling-Lawley trace will result in large values, and the null hypothesis will be rejected. The second criterion that approves the null test is Pillai's trace. This is a positive value of statistics ranging from 0 to 1 and is calculated using the following equation:

$V=\operatorname{Trace}\left(H(H+E)^{-1}\right)$

If $H$ is large relative to $E$, then Pillai's trace will result in bigger values, and a null hypothesis will be rejected.

In LPBF process, parameters are independent but should be adjusted according to each other. Wilk's Lambda is used to verify the other two criteria. A value of zero means that there is no variance explained by the independent variable (which is ideal). Therefore, the closer to zero the statistic is, the more the variable in question contributes to the model. The null hypothesis is rejected when Wilk's lambda is close to zero, although this should be done in combination with a small $p$ value.

$\Lambda=\frac{|E|}{|H+E|}$

Table 6 shows that the most influential factors on the parallel and angled surfaces are heat treatment, hatch space, laser power, scan speed and scan pattern angle. However, for perpendicular surfaces, different conditions were observed. For perpendicular surfaces, the rating of the effective parameters from the highest to the lowest is heat treatment, laser power, hatch space, scan pattern angle and scan speed. To prove this trend, Taguchi analysis was carried out in the next step.

\subsubsection{Effective parameters by Taguchi analysis}

Ranking of influential parameters is a direct factor of Delta. So, this factor is calculated based on Taguchi analysis; the highest Delta corresponds to the most effective parameter. Table 3 shows the average of the response characteristics at each level of the factor.

As can be seen in Table 3, the most influential factors on the parallel and angled surfaces are heat treatment and hatch spacing followed by scan speed, laser power and scan pattern angle. This result confirms the MANOVA (Appendix). On the other hand, for perpendicular surfaces, a different trend was observed. The most influential factor was similar to parallel and angled, which was heat treatment. The following factors are laser power, hatch space, pattern angle and scan speed. The reason and mechanism of these phenomena are explained in the following section.

\section{Discussion}

\subsection{Interaction of process parameters on the surface profile for parallel and angled measurements}

\subsubsection{Laser power}

The results of the interaction plots for different process parameters and heat treatment for the parallel and angled surfaces showed a similar trend. Figure $4 \mathrm{a}-\mathrm{d}$ show that by increasing laser power, the value of roughness decreased up to $30 \%$, for all samples. Surface roughness is directly related to melting pool size, energy density and subsequently temperature. When higher laser power is selected, the energy density and melting pool temperature based on Eqs. 8 and 9 increase [2, 23, 24]. 
Table 3 Response and means table for $R_{\mathrm{a}}$ parallel, angled and perpendicular

\begin{tabular}{|c|c|c|c|c|c|c|c|c|c|c|c|}
\hline & \multicolumn{6}{|c|}{ Response table for signal to noise ratios } & \multicolumn{5}{|c|}{ Response table for means } \\
\hline & Level & $\mathrm{LP}(\mathrm{W})$ & $\mathrm{SS}(\mathrm{mm} / \mathrm{s})$ & $\mathrm{HS}(\mu \mathrm{m})$ & $\mathrm{SP}\left({ }^{\circ}\right)$ & $\mathrm{HT}\left({ }^{\circ} \mathrm{C}\right)$ & $\mathrm{LP}(\mathrm{W})$ & $\mathrm{SS}(\mathrm{mm} / \mathrm{s})$ & $\mathrm{HS}(\mu \mathrm{m})$ & $\mathrm{SP}\left({ }^{\circ}\right)$ & $\mathrm{HT}\left({ }^{\circ} \mathrm{C}\right)$ \\
\hline \multirow{7}{*}{$\begin{array}{l}\text { Signal to noise and } \\
\text { main effect analysis } \\
\text { for } R_{\mathrm{a}} \text { parallel }\end{array}$} & 1 & -80.37 & -77.71 & -79.00 & -80.02 & -79.37 & 10,927 & 7879 & 9634 & 10,347 & 9495 \\
\hline & 2 & -80.93 & -80.05 & -78.39 & -80.05 & -76.72 & 11,186 & 10,452 & 8472 & 10,347 & 7297 \\
\hline & 3 & -78.03 & -79.46 & -79.49 & -79.81 & -78.96 & 8407 & 9981 & 9924 & 9927 & 9126 \\
\hline & 4 & -78.62 & -79.93 & -79.31 & -78.44 & -82.28 & 9234 & 10,231 & 9503 & 8927 & 13,109 \\
\hline & 5 & -79.92 & -80.72 & -81.69 & -79.55 & -80.54 & 10,172 & 11,385 & 12,394 & 10,379 & 10,900 \\
\hline & Delta & 2.91 & 3.01 & 3.30 & 1.62 & 5.56 & 2779 & 3506 & 3922 & 1452 & 5812 \\
\hline & Rank & 4 & 3 & 2 & 5 & 1 & 4 & 3 & 2 & 5 & 1 \\
\hline \multirow{7}{*}{$\begin{array}{l}\text { Signal to noise and } \\
\text { main effect analysis } \\
\text { for } R_{\mathrm{a}} \text { angled }\end{array}$} & 1 & -81.12 & -78.36 & -79.32 & -79.30 & -79.91 & 11,953 & 8351 & 9487 & 9386 & 9989 \\
\hline & 2 & -79.92 & -80.10 & -78.01 & -80.83 & -77.57 & 9968 & 10,306 & 8084 & 11,334 & 7610 \\
\hline & 3 & -79.70 & -80.30 & -80.61 & -79.63 & -78.56 & 10,140 & 10,829 & 10,983 & 9704 & 8732 \\
\hline & 4 & -78.86 & -79.86 & -79.95 & -79.90 & -82.23 & 9209 & 10,400 & 10,298 & 10,325 & 13,254 \\
\hline & 5 & -79.73 & -80.71 & -81.44 & -79.67 & -81.07 & 9902 & 11,286 & 12,319 & 10,422 & 11,587 \\
\hline & Delta & 2.26 & 2.35 & 3.43 & 1.53 & 4.66 & 2744 & 2936 & 4235 & 1949 & 5644 \\
\hline & Rank & 4 & 3 & 2 & 5 & 1 & 4 & 3 & 2 & 5 & 1 \\
\hline \multirow{7}{*}{$\begin{array}{l}\text { Signal to noise and } \\
\text { main effect analysis } \\
\text { for } R_{\mathrm{a}} \text { perpendicular }\end{array}$} & 1 & -80.07 & -79.73 & -80.28 & -80.04 & -79.79 & 10,156 & 9950 & 10,401 & 10,292 & 9818 \\
\hline & 2 & -81.77 & -80.76 & -78.47 & -80.52 & -79.05 & 12,352 & 11,022 & 8840 & 10,888 & 9156 \\
\hline & 3 & -80.37 & -80.17 & -80.24 & -80.79 & -78.89 & 10,807 & 10,584 & 10,500 & 11,175 & 9033 \\
\hline & 4 & -79.43 & -79.89 & -80.07 & -80.13 & -82.39 & 9715 & 10,319 & 10,175 & 10,323 & 13,265 \\
\hline & 5 & -78.82 & -79.90 & -81.40 & -78.96 & -80.34 & 8868 & 10,023 & 11,983 & 9219 & 10,626 \\
\hline & Delta & 2.94 & 1.03 & 2.93 & 1.83 & 3.51 & 3484 & 1073 & 3143 & 1957 & 4232 \\
\hline & Rank & 2 & 5 & 3 & 4 & 1 & 2 & 5 & 3 & 4 & 1 \\
\hline
\end{tabular}

LP is laser power, SS is scan speed, HS is hatch space, PA is laser-pattern angle and HT is heat treatment

When melt pool is solidified before the laser completely passes the current track, hatch distance does not affect the energy density, so the approximation of volumetric energy density is obtained according to Eq. 8 [2]. In this equation, $\eta$ is the absorption coefficient, $L_{\mathrm{P}}$ is laser power, $S_{\mathrm{S}}$ is scan speed and $B_{\mathrm{A}}$ is beam area. In order to melt the material, enough heat and energy are needed to increase enthalpy. The enthalpy for Ti-6Al-4V is a function of temperature in a solid phase, solid liquid (melting) and the liquid phase.

$E_{d}=\frac{\eta L_{P}}{S_{S} B_{A}}$

$E_{d}=\int_{T_{0}}^{T_{s}} C_{p_{s}} d T+\Delta H_{m}+\int_{T_{l}}^{T_{m p}} C_{p_{m}} d T$

Figure 5 shows the variation of specific heat versus temperature. Thus, to obtain the relation of specific heat versus temperature, different regressions were carried out, and the best results were obtained from the linear model. Specific heat in the melting phase is constant; however, it has different values versus temperature in the solid phase. Linear equation and the value of enthalpies are presented as follows.

$$
\begin{gathered}
C_{P_{s}}=0.474793+(0.000240253) T-\left(1.62089 \times 10^{-8}\right) T^{2} \text { for } T=298 \mathrm{~K}-1268 \mathrm{~K} \\
C_{P_{s}}=0.411245+(0.00018196) T-\left(5.89678 \times 10^{-10}\right) T^{2} \text { for } T=1268 \mathrm{~K}-T_{s} \\
C_{P_{m}}=0.831 \frac{\mathrm{J}}{\mathrm{gr} \cdot{ }^{\circ} \mathrm{K}} \text { for } T=1923 \mathrm{~K} \text { and Higher } \\
\Delta H_{\text {phase change }}=48 \frac{\mathrm{J}}{\mathrm{gr}} \\
\Delta H_{m}=360 \frac{\mathrm{J}}{\mathrm{gr}}
\end{gathered}
$$

To balance Eq. 9 on the right-hand side, the enthalpy is multiplied in density. The density of Ti-6Al-4V has different trends versus temperature, which is shown in Fig. 6. Therefore, for each section of Fig. 6, the value of density was approximated by the regression model.

When heating Ti-6Al-4V in $1268 \mathrm{~K}$, the material goes to phase transformation and needs more energy; therefore, considering enthalpy in different conditions, the value of energy density is obtained through Eq. 10.

$$
\begin{aligned}
E_{d}= & \int_{T_{0}}^{1268} C_{p_{s}} d T+\Delta H_{\text {phase change }}+\int_{1268}^{1878} C_{p_{s}} d T+\Delta H_{m} \\
& +\int_{1923}^{T_{m p}} C_{p_{m}} d T
\end{aligned}
$$

By solving Eq. 10 based on melt pool temperature $\left(T_{\mathrm{mp}}\right)$ that is in the border of the last integral, the approximation of $T_{\mathrm{mp}}$ is obtained by Eq. 11: 


\section{Contour Plots of Ra Parallel}
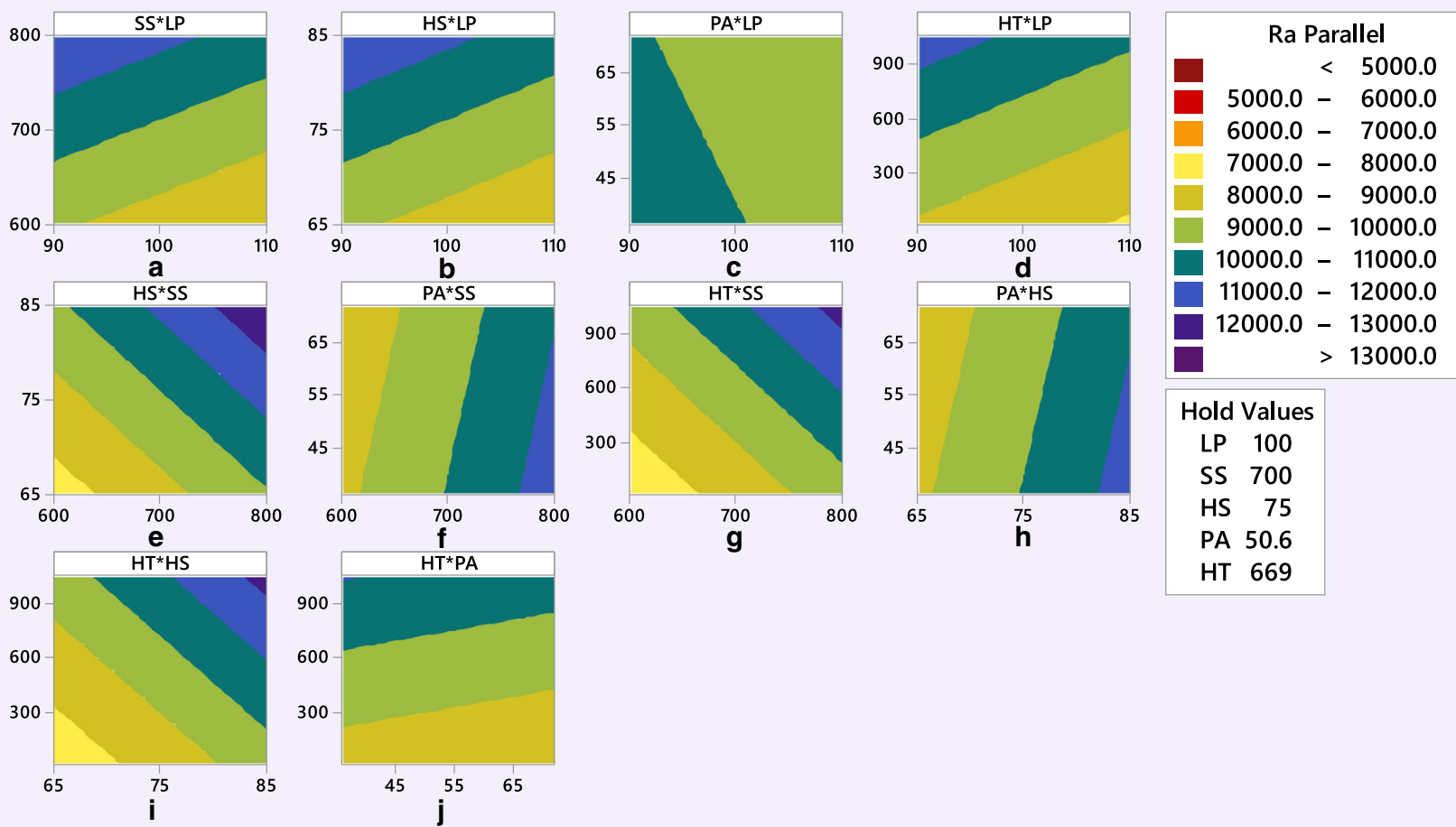

Fig. 4 Contour plots for the interaction of process parameters in parallel measurements

$T_{m p}=\frac{E_{d}-\left(\int_{T_{0}}^{1268} C_{p_{s}} d T+\Delta H_{\text {phase change }}+\int_{1268}^{1878} C_{p_{s}} d T+\Delta H_{m}\right)+\left(C_{p_{m}} \times 1923\right)}{C_{p_{m}}}$

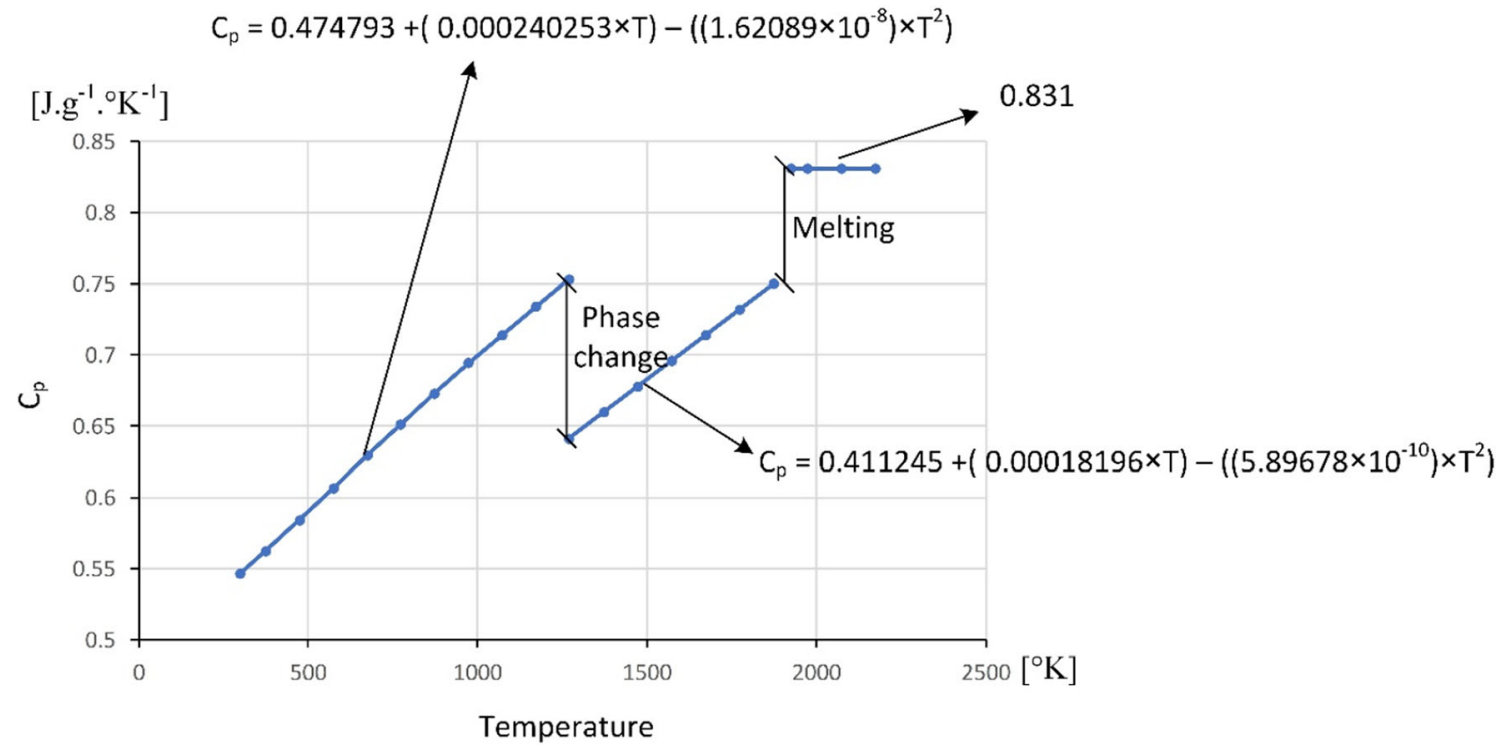

Fig. 5 Special heat capacity related to temperature [25] 
Fig. 6 Density related to temperature [25]

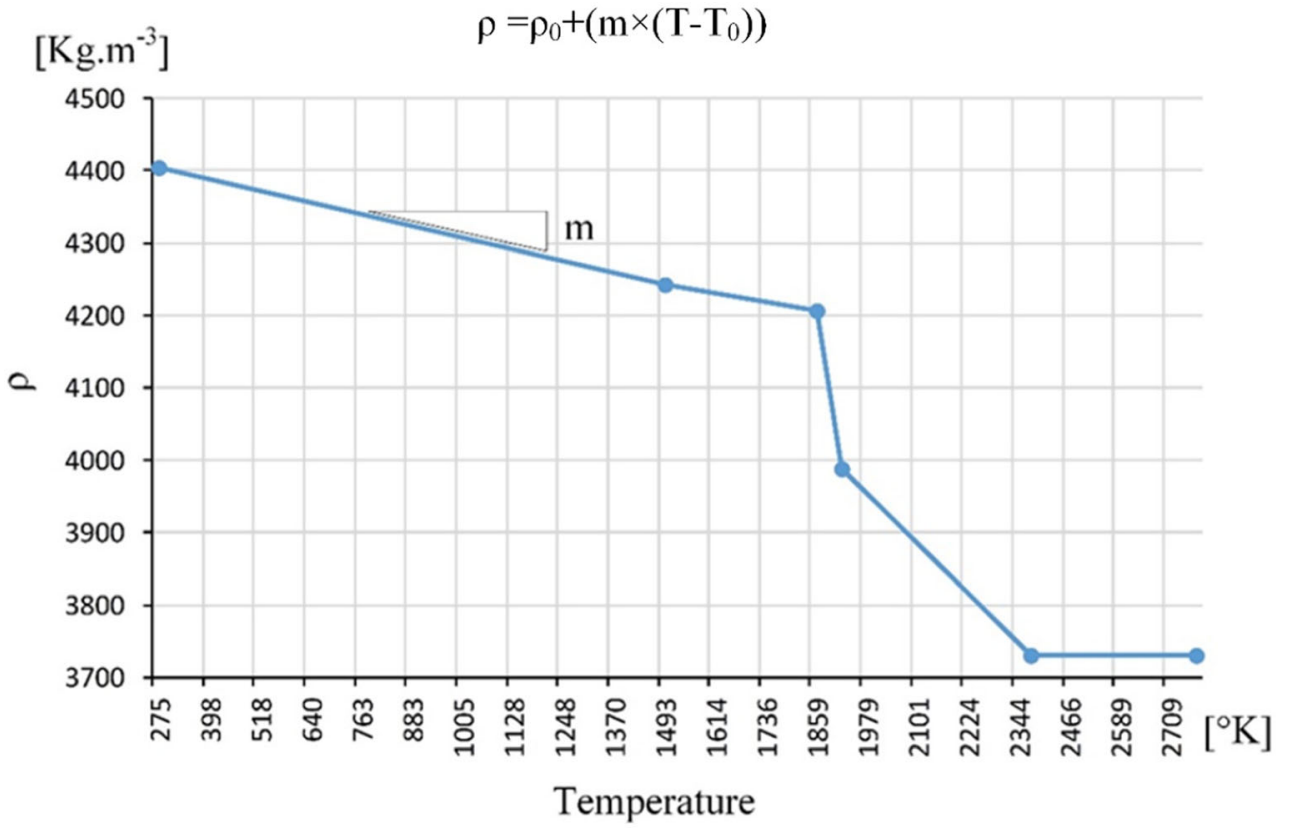

The width of the track is related to laser power, scan speed and the interaction between these two parameters. Higher laser power and lower scan speed produce higher temperature and based on Eq. 12 decreasing surface tension from 1.52 to 0.8
$\mathrm{N} / \mathrm{m}$. This leads to forming a low viscosity (Eq. 10) melting pool, which in turn leads to increased wettability and decreased Rayleigh instability [26, 27].

$\gamma=\gamma_{0}+\left[\frac{\delta \gamma}{\delta T} \times\left(\frac{E_{d}-\left(\int_{T_{0}}^{1268} C_{p_{s}} d T+\Delta H_{\text {phase change }}+\int_{1268}^{1878} C_{p_{s}} d T+\Delta H_{m}\right)+\left(C_{p_{m}} \times 1923\right)}{C_{p_{m}}}-T_{0}\right)\right]$

In Eq. 12, $\gamma_{0}$ and $T_{0}$ are reference values of surface tension and temperature, while $\frac{\delta \gamma}{\delta T}$ is the slope of the linear equation (Fig. 7). The reference values of temperature and surface tension are listed in Table 4:

Fig. 7 The trend of surface tension versus temperature (the concept of Marangoni's effect)
In Eqs. 8, 9 and 12, absorption ratio, specific heat capacity, latent heat of fusion and critical temperature are the thermophysical properties of the material. Meanwhile, laser power, scanning speed, beam area and $T_{0}$ are process

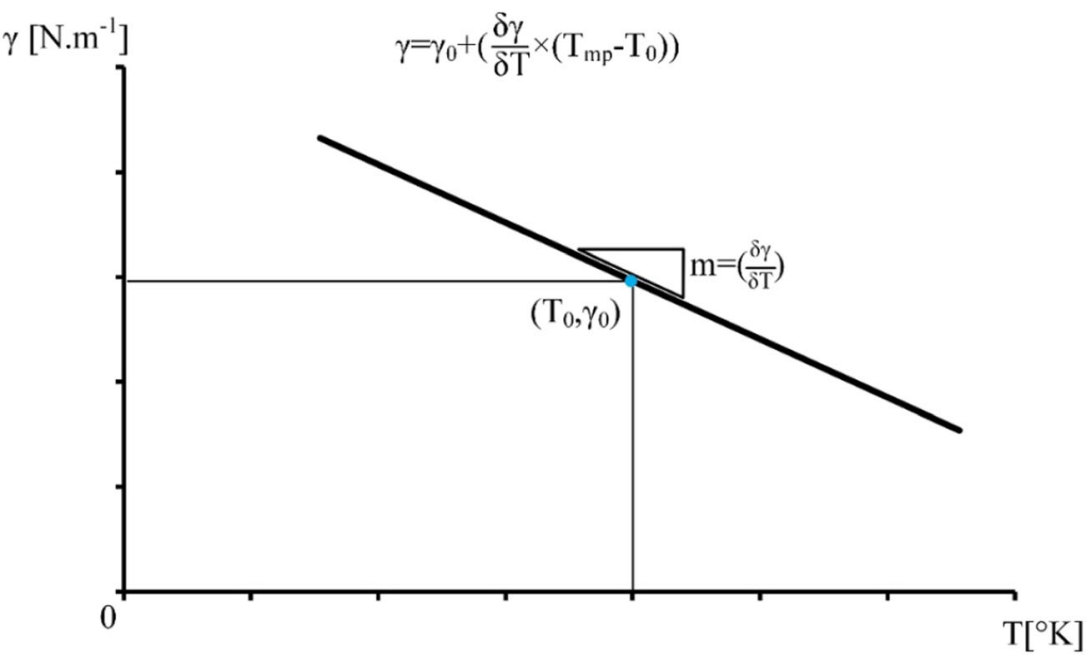


Table 4 Reference values for temperature and surface tension [28, 29]

\begin{tabular}{llll}
\hline Parameter & $\gamma_{0}\left[\frac{N}{m}\right]$ & $T_{0}[K]$ & $\frac{\delta \gamma}{\delta T}\left[\frac{N}{K . m}\right]$ \\
\hline Value & 1.52 & 1923 & $-5.52 \times 10^{-04}$ \\
\hline
\end{tabular}

parameters that have to be selected by operators so the effect of these parameters has been studied on surface tension in the next section.

Equations 8 and 11 show that increasing laser power and preheating $\left(T_{0}\right)$ increase the melting pool temperature. Scanning speed and beam diameter have a reverse relation with melting pool temperature. Equation 12 shows that by increasing melting pool temperature, the value of bracket increases, and due to the negative slope in Fig. 7, the value of surface tension $(\gamma)$ decreases. This phenomenon is called the thermocapillary effect. Table 5 presents the calculated surface tension and melt pool temperature for each experiment.

\subsubsection{Scan speed}

Based on Taguchi and MANOVA, scan speed has a higher impact on parallel and angled surfaces, so the direction of the contour colours was generally formed toward scan speed (Figs. 4, 8 and 12a). In higher scan speed, due to Rayleigh instability and lack of wetting, the roughness of the parallel and angled surface increased (Fig. 4a, e, f and g). For higher scan speed $(800 \mathrm{~mm} / \mathrm{s})$, the value of surface tension obtained $1.22-1.52 \mathrm{~N} / \mathrm{m}$, while for lower scan speed $(600 \mathrm{~mm} / \mathrm{s})$, surface tension ranging $0.8-1.10 \mathrm{~N} / \mathrm{m}$ was obtained. The wettability of the melting pool is defined by the spreading parameter "S". According to Eq. 11, the type of spreading can be film or droplet [24, 30-33].

$$
\left\{\begin{array}{c}
S=\gamma_{S G}-\left(\gamma_{S L}+\gamma_{L G}\right) \\
\text { If } S>0 \Rightarrow \text { Film appears } \\
\text { If } S<0 \Rightarrow \text { Droplet appears }
\end{array}\right.
$$

By increasing scan speed according to Eq. 12, the value of melting pool temperature decreases, and on account of the thermocapillary effect, the value of surface tension increases, more specifically in the liquid phase $\left(\gamma_{S L}+\gamma_{L G}\right)$; therefore, $S$ $<0$ and the droplet appears on the surface.

In contour colour-plotted diagrams, the area of low energy density has a lower temperature and higher surface tension.
Table 5 The calculated surface tension and approximation of melting pool temperature

\begin{tabular}{|c|c|c|c|c|}
\hline Test no & Laser power $[\mathrm{W}]$ & Scan speed $[\mathrm{mm} / \mathrm{min}]$ & $\gamma\left[\frac{N}{m}\right]$ & $T_{\mathrm{mp}}[K]$ \\
\hline 1 & 90 & 600 & 1.10 & 2678.67 \\
\hline 2 & 90 & 650 & 1.21 & 2488.99 \\
\hline 3 & 90 & 700 & 1.32 & 2289.90 \\
\hline 4 & 90 & 750 & 1.43 & 2092.29 \\
\hline 5 & 90 & 800 & 1.52 & 1931.11 \\
\hline 6 & 95 & 600 & 1.03 & 2815.66 \\
\hline 7 & 95 & 650 & 1.14 & 2615.44 \\
\hline 8 & 95 & 700 & 1.23 & 2443.83 \\
\hline 9 & 95 & 750 & 1.34 & 2244.59 \\
\hline 10 & 95 & 800 & 1.44 & 2064.73 \\
\hline 11 & 100 & 600 & 0.95 & 2952.66 \\
\hline 12 & 100 & 650 & 1.07 & 2741.90 \\
\hline 13 & 100 & 700 & 1.17 & 2561.25 \\
\hline 14 & 100 & 750 & 1.25 & 2404.69 \\
\hline 15 & 100 & 800 & 1.36 & 2205.62 \\
\hline 16 & 105 & 600 & 0.88 & 3089.65 \\
\hline 17 & 105 & 650 & 1.00 & 2868.35 \\
\hline 18 & 105 & 700 & 1.10 & 2678.67 \\
\hline 19 & 105 & 750 & 1.19 & 2514.28 \\
\hline 20 & 105 & 800 & 1.28 & 2355.14 \\
\hline 21 & 110 & 600 & 0.80 & 3226.64 \\
\hline 22 & 110 & 650 & 0.93 & 2994.81 \\
\hline 23 & 110 & 700 & 1.04 & 2796.09 \\
\hline 24 & 110 & 750 & 1.13 & 2623.87 \\
\hline 25 & 110 & 800 & 1.22 & 2473.18 \\
\hline
\end{tabular}


These lead to produce lower wetting and higher viscosity, as well as lack of fusion, which decreases the surface quality [34]. Moreover, in the melting pool, bubbles often form along contact surfaces. The pressure of the bubbles is obtained from Laplace's law according to Eq. 14:

$P=\frac{\gamma}{R_{\text {cur }}}$

In the case of higher scan speed and hatch space and lower laser power (Figs. 4a and $\mathrm{g}$ and $8 \mathrm{a}$ and $\mathrm{g}$ ), lower energy density leads to higher surface tension and subsequently higher bubble pressure. Bursting and splashing are the results of this phenomenon, and rough surface is formed; therefore, surface quality reduces in agreement to the literature $[35,36]$.

\subsubsection{Hatch space and pattern angle}

Increasing hatch space has both positive and negative effects on the quality of the surface. By increasing the hatch space, less overlap area is generated. In the overlap area, due to higher viscosity and mush phase, the interaction of surface tension and hydrostatic force versus vapour pressure is not balanced, and keyholes and fusion appear, hence increasing the value of surface roughness. Also, due to the lack of Marangoni's convection, accumulated heat increases the chance of cracks, more specifically when the temperature of the melting pool is high [37, 38]. Moreover, in the case of lower hatch space due to higher overlap, some of the ripples were covered by the overlapping of subsequent hatching. Thus, smoother surfaces are formed as a consequence of the interaction of these two phenomena. Figures 4 and $8 \mathrm{~b}, \mathrm{e}, \mathrm{h}$ and i indicated that by increasing the hatch space (interacting with other process parameters), the value of surface roughness for parallel and angled measurements increased (Fig. 8). As can be seen in Fig. 9c, increasing the hatch space leads to the formation of uncovered areas with a circular shape and deposited particles situated around this area. This is a possible crack initiation region and reduces surface quality.

Figures 4 and $8 \mathrm{e}$ show that in the area of lower energy density including higher scan speed and hatch distances, the rougher surface was obtained. This is related to the thermocapillary effect and increasing surface tension (as a result of decreasing energy density and melting pool temperature Eqs. 9 and 12). Therefore, the surface tension, in conjunction with the liquid phase $\gamma_{\mathrm{SL}}$ and $\gamma_{\mathrm{LG}}$, increased, and according to Eq. 13, lack of wettability results in lower surface quality. The surface tension for lower scan speed was obtained 1.9-fold bigger than higher scan speed. The interaction of hatch space and pattern angle in Figs. 4 and 8h shows that by increasing pattern angle, small variations on the value of surface roughness were obtained in agreement with the results of the MANOVA and Taguchi analysis.

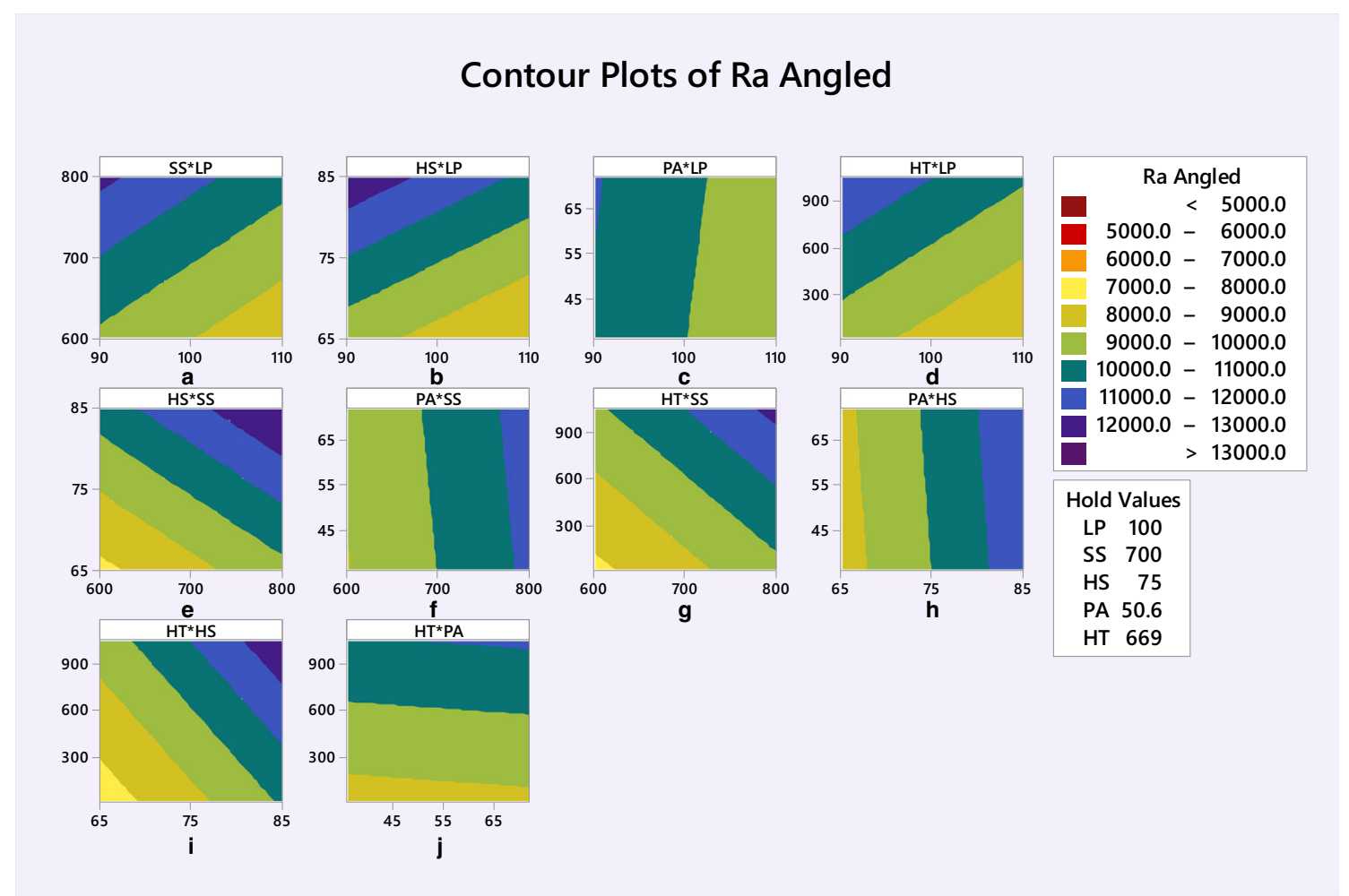

Fig. 8 Contour plots for the interaction of process parameters for angled measurements 
Fig. 9 The effect of hatch space on ripples

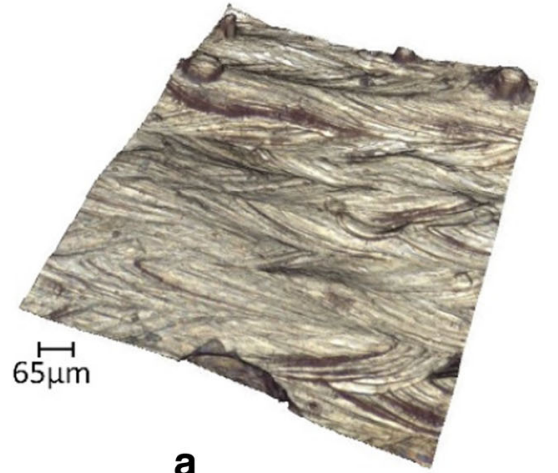

a

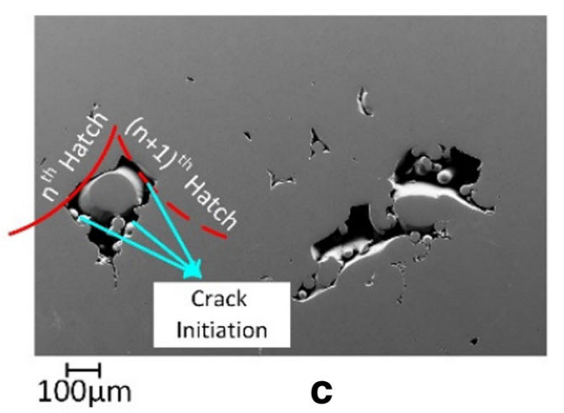

b

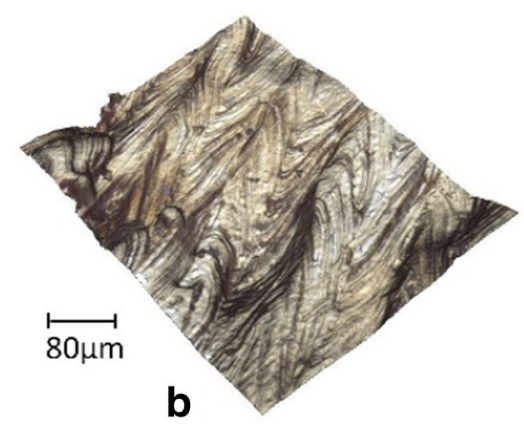

The interaction of laser pattern incremental angle versus other process parameters showed that this parameter has the lowest impact on the surface roughness for parallel and angled measurements. Therefore, the effect of this factor on the formation of surface profile can be neglected.

\subsubsection{Heat treatment}

Heat treatment was found to be the most influential parameter on the surface roughness for both parallel and angled measurements. When the samples are heat treated on the $\alpha+\beta$ phase, the formation of $\beta$ (due to inherent soft characteristic) and softening occurs. In this heat treatment, the $\beta$ transformation is directly related to the cooling rate [21,39-41]. In our case, the cooling rate was relatively slow $\left(5^{\circ} \mathrm{C} / \mathrm{min}\right)$, and $\beta$ is transferred to secondary $\alpha$ lamellae, so the softened material on the surface moved in microscale. The effect of heat treatment on the lowest and the best surface was shown in Fig. 10.

As can be seen in $\beta$ annealing, dropped particles on the top surfaces fused and micro-movement of softened materials result in large valleys, and the surface quality radically decreased. The common defects in LPBF are balling, unstable melting pool, residual particle, spattering, etc. which form peak and valleys and in $\beta$ heat treatment. Some unmelted particles on valleys are fused on the top surface and result in poor surface quality in agreement to the literature [18, 20,42]. Moreover, LPBF is working under a controlled atmosphere with the presence of inert gas, but the small value of some elements such as oxygen and nitrogen [43] that are common contamination in LPBF of Ti leads to a decrease in the melting temperature of titanium, causing micro-flow and production of rougher surfaces, as shown in Fig. 10.

\subsection{Interaction process parameters on the surface profile for perpendicular measurements}

\subsubsection{Laser power}

For surface roughness measurement that is perpendicular to the scan direction, contour plots show that increasing laser power improved surface quality. This is related to the explained phenomena such as pressure in droplets and wettability.

Increasing laser power also increases recoil pressure, more specifically in the radial direction (toward overlapping area). In the overlap area, the gradient of melting fluid speed is zero, and more heat is accumulated in this region.

$\nabla \overrightarrow{u_{f b}}=\frac{\partial u_{f b}}{\partial x} \widehat{i}+\frac{\partial u_{f b}}{\partial y} \widehat{j}+\frac{\partial u_{f b}}{\partial z} \widehat{k} \neq 0$

Recoil is a rheological phenomenon that happens only in non-Newtonian fluids and is defined by a moving fluid's ability to snap back to a previous position when external forces are removed. This phenomenon is a result of the fluid's elasticity and memory and is related to the molecular structure, the location and shape of the fluid. This pressure is associated with conformational entropy [44]. Almost all molten metal are non-Newtonian. Molten metal could exhibit both timeindependent (but stress-dependent) and time-dependent (when 

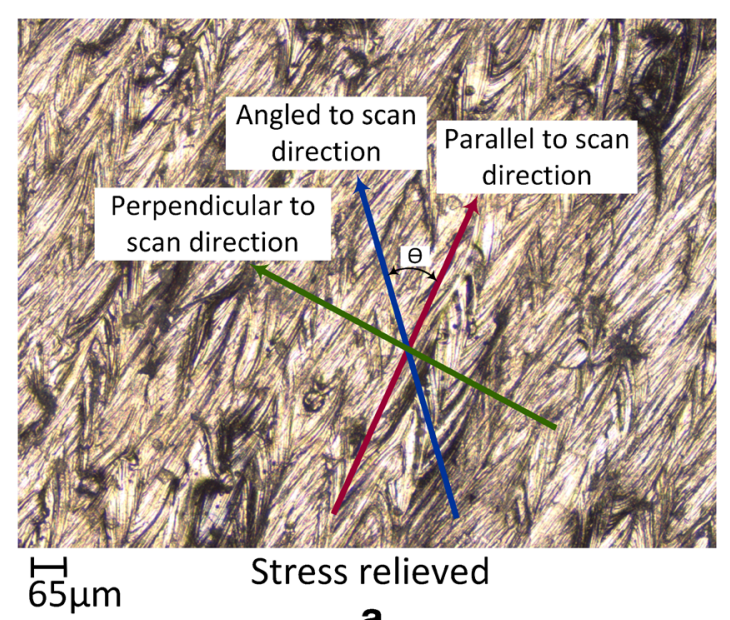

Stress relieved

a

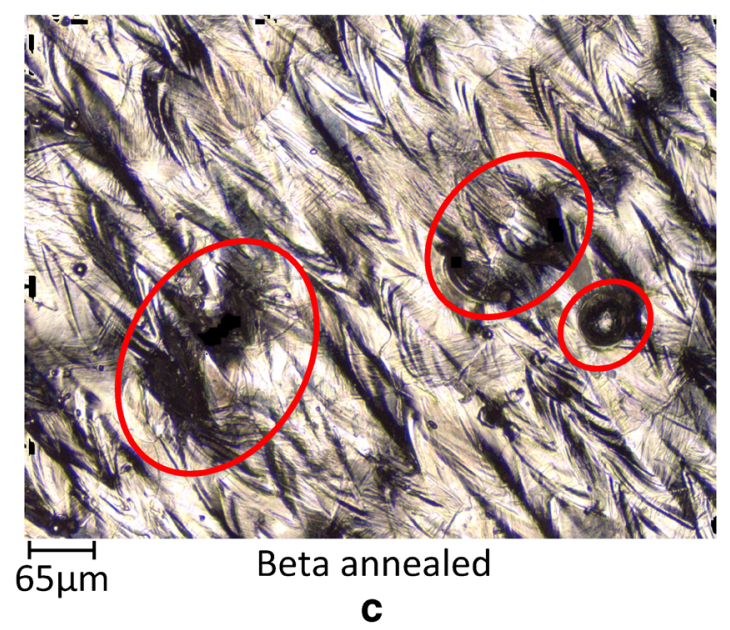

Fig. 10 Measurement directions and defects on annealed samples

sheared at a constant rate) properties. Sometimes, they display a mix of both types of behaviour. In AM, the pressure of the laser produces the source of the snapback movement. The effect of recoil pressure is called a ripple effect, which can be seen on the top surface of LPBF parts and is obtained according to the following equation [44]:

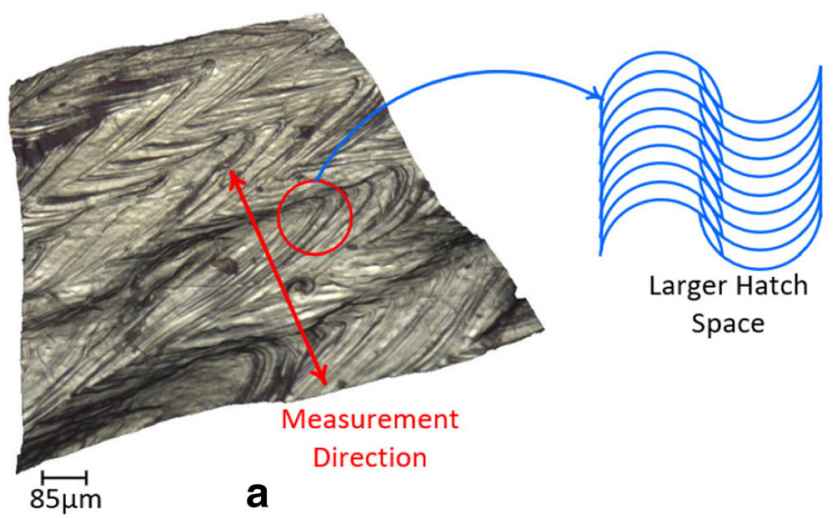

Fig. 11 Higher hatch space and the ripple effect
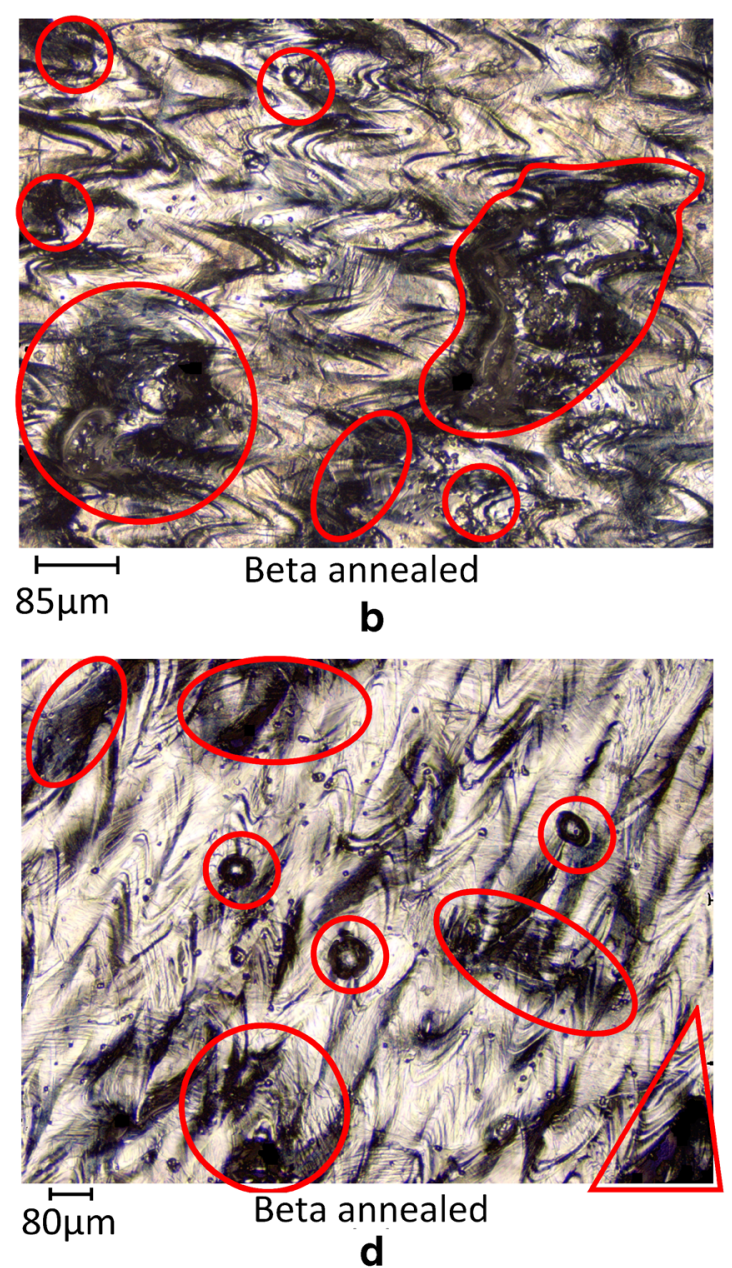

$P_{\text {recoil }}=P_{0} \exp \left[\frac{\Delta H_{V}}{R_{g}}\left(\frac{1}{T_{V}}-\frac{1}{T_{m p}}\right)\right]$

By the substitution of process parameters (Eq. 8) on Eq. 16, recoil pressure in LPBF is defined according to Eq. 17:

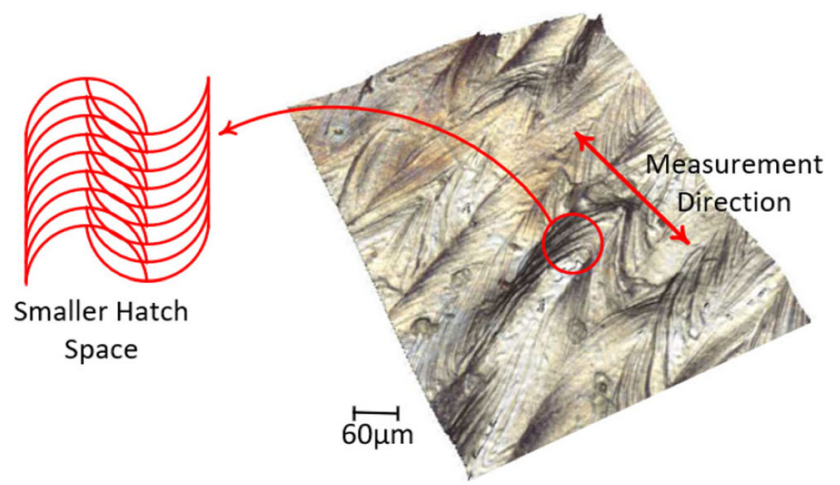

b 


$$
P_{\text {recoil }}=P_{0} \exp \left[\frac{\left(\delta Q+V d P_{c h}-\delta W_{S U}\right)}{R_{g}}\left(\frac{1}{T_{V}}-\frac{1}{T_{m p}}\right)\right]
$$

Surface pressure in the work chamber is constant, and by supposing no additional work inside the chamber " $W_{s u}$ ", the recoil pressure is defined according to Eq. 18.

$P_{\text {recoil }}=P_{0} \exp \left[\frac{\delta Q}{R_{g}}\left(\frac{1}{T_{V}}-\frac{1}{T_{m p}}\right)\right]$

In addition, enthalpy is a function of heat $d h=\delta Q$; therefore, according to Eq. 8, increasing energy density leads to increasing temperature, and generated heat on the surface of the melting pool and subsequently recoil pressure increases. When the temperature increased, due to the thermocapillary effect, surface tension decreased, and radial recoil pressure induces higher Marangoni's convection. This led to transfers of the accumulated heat from the bottom of the overlap area to the melting pool surface, and so vapour pressure reduced. This provides less chance for the formation of keyholes, and surface quality improves.

\subsubsection{Scan speed}

When increasing scan speed, almost no change was observed on surface roughness in perpendicular measurements. This is shown in Table 3 and Table 6. Furthermore, fitted line plots and contour colour diagrams illustrate very small variations of roughness in perpendicular scan direction were observed. The reason is any phenomenon that happens due to the variation of scan speed is associated with the parallel direction. Therefore, when measuring roughness perpendicular to scan movement, the chance of happening the mentioned phenomena and defects is less.

\subsubsection{Hatch space and scan pattern angle}

Similar to parallel and angled measurements, by increasing the hatch space, the value of roughness for perpendicular measurement increases. This can be related to increasing the chance of formation of radial ripples which increases the number of peaks in each measurement and increases the value of roughness. Increasing the roughness in radial (perpendicular) direction due to the ripples has two times more effect on the value of roughness (Fig. 11).

Based on Fig. 12b, e and h, increasing hatch space increases the value of surface roughness in perpendicular measurements. The mentioned radial mechanism is stronger than the positive effect of decreasing the overlap area for the bigger hatches. The size and number of ripples are significantly larger than overlap defects. Scan pattern angle showed similar behaviour to scan speed on surface roughness of perpendicular direction. MANOVA and Taguchi analysis showed that the pattern angle does not have a significant effect on the value of roughness. As expected, a small reduction of roughness in

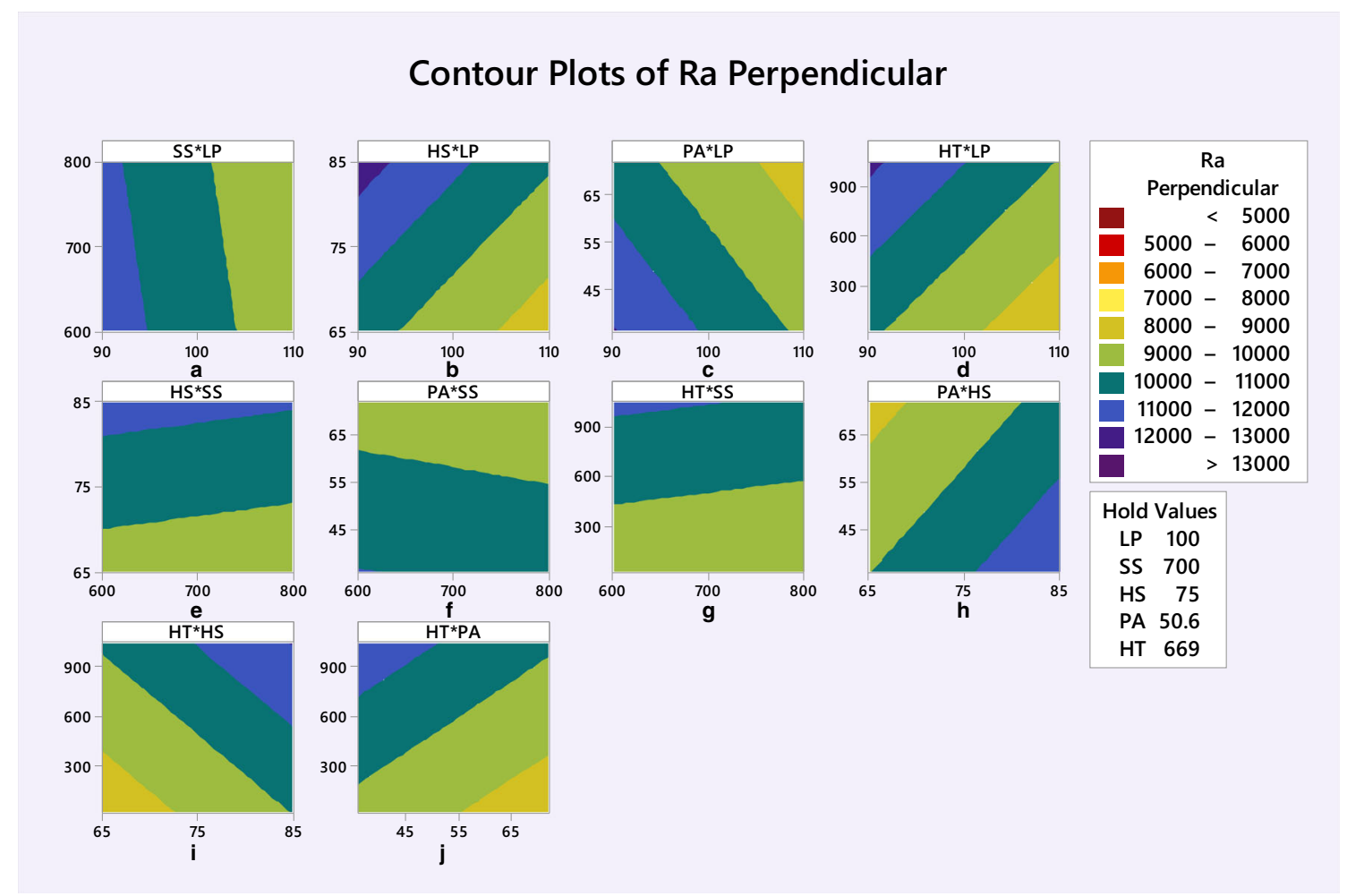

Fig. 12 Contour plots for the interaction of process parameters for perpendicular measurements 
the perpendicular direction was observed by increasing the pattern angle (Fig. 12c, f and h).

\subsubsection{Heat treatment}

Heat treatment, similar to parallel and angled measurements, was found to be the most effective parameter on the surface roughness. Similar phenomena that were explained for other measurement directions affect the surface roughness in the perpendicular scan movement. These comprise softening in higher temperature, the fusion of dropped particles, micromotion and the effect of other elements to decrease the melting temperature [21, 39-41, 45].

\section{Conclusion}

In this research, we developed a physical model to estimate the melting pool temperature and surface tension of LPBF Ti$6 \mathrm{Al}-4 \mathrm{~V}$ by using the process parameters, including laser power, scan speed, hatch space and pattern angle. Thermophysical properties of the material including density and specific heat have non-linear behaviour versus the temperature for solid, semi-solid and liquid phases; however, they are constant in the melting phase. To obtain the relation of specific heat and density versus temperature, linear regressions (that showed the best results) were used. Therefore, to estimate the melting pool temperature and surface tension, a multicomponent integral model was used for different temperatures and phases.

A statistical model showed the effect of different process and post-process parameters on the value of surface tension and the generated surface quality for different directions (parallel, angled and perpendicular) to the scan movement. Thermophysical properties and rheological phenomena are shown to be the main driving factors for melting pool temperature, surface tension and forming the surface profile. The ranking of the most to the least effective parameters at the parallel and angled surfaces was obtained as heat treatment $>$ hatch space $>$ scan speed $>$ laser power $>$ scan pattern angle.
Higher laser power and lower scan speed produce higher temperature; therefore, surface tension reduces from 1.52 to $0.8 \mathrm{~N} / \mathrm{m}$. This results in forming a low viscosity melting pool, which in turn leads to increased wettability and decreased Rayleigh instability, and surface roughness in all directions improved. For lower scan speed $(600 \mathrm{~mm} / \mathrm{s})$, surface tension ranging $0.8-1.10 \mathrm{~N} / \mathrm{m}$ was obtained, while for higher scan speed $(800 \mathrm{~mm} / \mathrm{s})$, the value of surface tension obtained $1.22-1.52 \mathrm{~N} / \mathrm{m}$. By increasing scan speed and surface tension, specifically in the liquid phase, the droplets appear on the surface which reduces the surface quality in parallel and angled measurements.

Lower energy density increased surface tension in conjunction with the liquid phase $\left(\gamma_{\mathrm{SL}}\right.$ and $\left.\gamma_{\mathrm{LG}}\right)$, and rougher surface due to lower wetting was obtained for parallel and angled surfaces.

Changing hatch space has both positive and negative effects on the quality of the surface. By increasing the hatch space, less overlap area is formed. In the overlap area, higher surface tension and viscosity increase the chance of defects, hence increasing the value of surface roughness. In contrast, increasing the hatch space produces uncovered areas with a circular shape and forms radial ripples and increases the number of peaks in each perpendicular measurement. The size and number of ripples are significantly larger than overlap defects, and rougher surfaces are obtained in perpendicular measurements.

In the case of lower hatch space and bigger overlap, some of the ripples were covered by the overlapping of next hatching, and smoother surfaces are formed for parallel and angled measurements. Almost all rheological phenomena that are related to the variation of scan speed are associated with a parallel direction, so they have less effect on perpendicular measurements

Acknowledgement The authors would like to thank Professor Bernard Rolfe for his help in drafting and technical review.

\section{Appendix}

Table 6 Multivariable analysis of variance for different process parameters $(s=1, m=1.0, n=1.0)$

\begin{tabular}{|c|c|c|c|c|c|c|c|c|c|c|}
\hline \multirow[t]{6}{*}{$\begin{array}{l}\text { Multivariable analysis for } \\
\text { parallel measurements }\end{array}$} & \multicolumn{2}{|c|}{$\begin{array}{l}\text { MANOVA tests for } \\
\text { laser power }(W)\end{array}$} & \multirow[b]{2}{*}{$F$} & \multirow[b]{2}{*}{$P$} & \multicolumn{3}{|c|}{$\begin{array}{l}\text { MANOVA tests for } \\
\text { scan speed }(\mathrm{mm} / \mathrm{s})\end{array}$} & \multicolumn{2}{|c|}{$\begin{array}{l}\text { MANOVA tests for } \\
\text { hatch spacing }(\mu \mathrm{m})\end{array}$} & \multirow[b]{2}{*}{$P$} \\
\hline & Criterion & $\begin{array}{l}\text { Test } \\
\text { statistic }\end{array}$ & & & $\begin{array}{l}\text { Test } \\
\text { statistic }\end{array}$ & $F$ & $P$ & $\begin{array}{l}\text { Test } \\
\text { statistic }\end{array}$ & $F$ & \\
\hline & Wilks' & 0.31021 & 2.224 & 0.229 & 0.26741 & 2.740 & 0.176 & 0.22375 & 3.469 & 0.128 \\
\hline & Lawley-Hotelling & 2.22365 & 2.224 & 0.229 & 2.73958 & 2.740 & 0.176 & 3.46934 & 3.469 & 0.128 \\
\hline & Pillai's & 0.68979 & 2.224 & 0.229 & 0.73259 & 2.740 & 0.176 & 0.77625 & 3.469 & 0.128 \\
\hline & Roy's & 2.22365 & & & 2.73958 & & & 3.46934 & & \\
\hline
\end{tabular}


Table 6 (continued)

\begin{tabular}{|c|c|c|c|c|c|c|c|c|c|c|}
\hline & \multicolumn{4}{|c|}{ MANOVA tests for scanning pattern angle $\left(^{\circ}\right)$} & \multicolumn{6}{|c|}{ MANOVA tests for heat treatment $\left({ }^{\circ} \mathrm{C}\right)$} \\
\hline & Criterion & Test statistic & $F$ & $P$ & \multicolumn{2}{|l|}{ Test statistic } & $F$ & \multicolumn{3}{|l|}{$P$} \\
\hline & Wilks' & 0.61255 & 0.633 & 0.666 & \multicolumn{2}{|l|}{0.11475} & 7.715 & \multicolumn{2}{|l|}{0.036} & \\
\hline & Lawley-Hotelling & 0.63253 & 0.633 & 0.666 & \multicolumn{2}{|l|}{7.71491} & 7.715 & \multicolumn{2}{|l|}{0.036} & \\
\hline & Pillai's & 0.38745 & 0.633 & 0.666 & \multicolumn{2}{|l|}{0.88525} & 7.715 & \multicolumn{2}{|l|}{0.036} & \\
\hline & Roy’s & 0.63253 & & & \multicolumn{3}{|l|}{7.71491} & & & \\
\hline \multirow[t]{12}{*}{$\begin{array}{l}\text { Multivariable analysis for } \\
\text { angled measurements }\end{array}$} & \multicolumn{4}{|l|}{$\begin{array}{l}\text { MANOVA tests for } \\
\text { laser power }(W)\end{array}$} & \multicolumn{3}{|c|}{$\begin{array}{l}\text { MANOVA tests for } \\
\text { scan speed }(\mathrm{mm} / \mathrm{s})\end{array}$} & \multicolumn{3}{|c|}{$\begin{array}{l}\text { MANOVA tests for } \\
\text { hatch spacing }(\mu \mathrm{m})\end{array}$} \\
\hline & Criterion & $\begin{array}{l}\text { Test } \\
\text { statistic }\end{array}$ & $F$ & $P$ & $\begin{array}{l}\text { Test } \\
\text { statistic }\end{array}$ & $F$ & $P$ & Test statistic & $F$ & $P$ \\
\hline & Wilks' & 0.09656 & 9.356 & 0.026 & 0.08171 & 11.238 & 0.019 & 0.04255 & 22.499 & 0.005 \\
\hline & Lawley-Hotelling & 9.35603 & 9.356 & 0.026 & 11.23800 & 11.238 & 0.019 & 22.49946 & 22.499 & 0.005 \\
\hline & Pillai's & 0.90344 & 9.356 & 0.026 & 0.91829 & 11.238 & 0.019 & 0.95745 & 22.499 & 0.005 \\
\hline & Roy's & 9.35603 & & & 11.23800 & & & 22.49946 & & \\
\hline & $\begin{array}{l}\text { MANOVA tests fo } \\
\text { scanning pattern }\end{array}$ & angle $\left({ }^{\circ}\right)$ & & & $\begin{array}{l}\text { MANOVA } \\
\text { heat treatı }\end{array}$ & $\begin{array}{l}\text { tests for } \\
\text { ment }\left({ }^{\circ} \mathrm{C}\right.\end{array}$ & & & & \\
\hline & Criterion & Test statistic & $F$ & $P$ & Test statistic & & $F$ & $P$ & & \\
\hline & Wilks' & 0.16590 & 5.028 & 0.073 & 0.02177 & & 44.933 & 0.001 & & \\
\hline & Lawley-Hotelling & 5.02757 & 5.028 & 0.073 & 44.93278 & & 44.933 & 0.001 & & \\
\hline & Pillai's & 0.83410 & 5.028 & 0.073 & 0.97823 & & 44.933 & 0.001 & & \\
\hline & Roy's & 5.02757 & & & 44.93278 & & & & & \\
\hline \multirow[t]{12}{*}{$\begin{array}{l}\text { Multivariable analysis for } \\
\text { perpendicular measurements }\end{array}$} & \multicolumn{2}{|l|}{$\begin{array}{l}\text { MANOVA tests for } \\
\text { laser power }(\mathrm{W})\end{array}$} & & & \multicolumn{3}{|c|}{$\begin{array}{l}\text { MANOVA tests for } \\
\text { scan speed }(\mathrm{mm} / \mathrm{s})\end{array}$} & \multicolumn{2}{|c|}{$\begin{array}{l}\text { MANOVA tests for } \\
\text { hatch spacing }(\mu \mathrm{m})\end{array}$} & \\
\hline & Criterion & $\begin{array}{l}\text { Test } \\
\text { statistic }\end{array}$ & $F$ & $P$ & $\begin{array}{l}\text { Test } \\
\text { statistic }\end{array}$ & $F$ & $P$ & $\begin{array}{l}\text { Test } \\
\text { statistic }\end{array}$ & $F$ & $P$ \\
\hline & Wilks' & 0.09957 & 9.043 & 0.028 & 0.49586 & 1.017 & 0.494 & 0.13164 & 6.597 & 0.047 \\
\hline & Lawley-Hotelling & 9.04269 & 9.043 & 0.028 & 1.01671 & 1.017 & 0.494 & 6.59653 & 6.597 & 0.047 \\
\hline & Pillai's & 0.90043 & 9.043 & 0.028 & 0.50414 & 1.017 & 0.494 & 0.86836 & 6.597 & 0.047 \\
\hline & Roy's & 9.04269 & & & 1.01671 & & & 6.59653 & & \\
\hline & \multicolumn{2}{|c|}{$\begin{array}{l}\text { MANOVA tests for } \\
\text { scanning pattern angle }\left(^{\circ}\right)\end{array}$} & & & \multicolumn{3}{|c|}{$\begin{array}{l}\text { MANOVA tests for } \\
\text { heat treatment }\left({ }^{\circ} \mathrm{C}\right)\end{array}$} & & & \\
\hline & Criterion & Test statistic & $F$ & $P$ & Test statistic & & $F$ & $P$ & & \\
\hline & Wilks' & 0.25188 & 2.970 & 0.158 & 0.05933 & & 15.856 & 0.010 & & \\
\hline & Lawley-Hotelling & 2.97008 & 2.970 & 0.158 & 15.85582 & & 15.856 & 0.010 & & \\
\hline & Pillai's & 0.74812 & 2.970 & 0.158 & 0.94067 & & 15.856 & 0.010 & & \\
\hline & Roy’s & 2.97008 & & & 15.85582 & & & & & \\
\hline
\end{tabular}

Categorical regression equation for parallel measurements

$$
\begin{aligned}
& \text { Ra parallel }=\exp \left(\mathrm{Y}^{\prime}\right) \\
& \mathrm{Y}^{\prime}=9.0118+0.0 \text { LP_90 }+0.06598 \text { LP_95-0.29530 LP_100-0.18298 LP_105-0.04563 LP_110 } \\
& +0.0 \text { SS_600 + 0.29947 SS_650 + 0.23439 SS_700 + 0.28641 SS_750 + 0.35921 SS_800 } \\
& +0.0 \text { HS_65-0.09703 HS_70 + 0.00978 HS_75 + 0.01731 HS_80 + 0.27853 HS_85 + 0.0 PA_36 } \\
& -0.01004 \text { PA_40-0.02901 PA_45-0.17999 PA_60-0.08007 PA_72 + 0.0 HT_20 } \\
& -0.30167 \text { HT_600-0.03428 HT_750 + } 0.33854 \text { HT_925 + 0.12600 HT_1050 }
\end{aligned}
$$

Categorical regression equation for angled measurements

$$
\begin{aligned}
& \text { Ra angled }=\exp \left(\mathrm{Y}^{\prime}\right) \\
& \mathrm{Y}^{\prime}=9.05131+0.0 \text { LP_90-0.14817 LP_95-0.17804 LP_100-0.25504 LP_105-0.15944 LP_110 } \\
& +0.0 \text { SS_600 + 0.20012 SS_650 + 0.21820 SS_700 + 0.18144 SS_750 + 0.27057 SS_800 } \\
& +0.0 \text { HS_65-0.14900 HS_70 + 0.13797 HS_75 + 0.07238 HS_80 + 0.22983 HS_85 + 0.0 PA_36 } \\
& +0.16946 \text { PA_40 }+0.04233 \text { PA_45 + } 0.06653 \text { PA_60 + 0.05003 PA_72 + } 0.0 \text { HT_20 } \\
& -0.26959 \text { HT_600-0.14480 HT_750 + } 0.26421 \text { HT_925 + 0.12840 HT_1050 }
\end{aligned}
$$


Categorical regression equation for perpendicular measurements

Ra perpendicular $=\exp \left(\mathrm{Y}^{\prime}\right)$

$$
\begin{aligned}
\mathrm{Y}^{\prime}= & 9.15933+0.0 \text { LP_90 }+0.19878 \text { LP_95 }+0.03453 \text { LP_100-0.06722 LP_105-0.13450 LP_110 } \\
& +0.0 \text { SS_600 }+0.10768 \text { SS_650 + 0.04483 SS_700 + 0.01920 SS_750 + 0.01429 SS_800 } \\
& +0.0 \text { HS_65-0.19656 HS_70-0.00370 HS_75-0.02507 HS_80 + 0.12460 HS_85 + 0.0 PA_36 } \\
& +0.04062 \text { PA_40 + 0.08170 PA_45-0.00684 PA_60-0.11916 PA_72 + 0.0 HT_20 } \\
& -0.07375 \text { HT_600-0.09418 HT_750 }+0.30183 \text { HT_925 }+0.07056 \text { HT_1050 }
\end{aligned}
$$

Continuous regression equation for parallel measurements

$$
\begin{aligned}
R_{a} \text { Parallel }= & 10^{-9772} \times L P^{3061} \times S S^{2647.8} \times H S^{-3481.4} \\
& \times P A^{-25.52} \times H T^{1.256} \times(L P \times S S)^{-613} \\
& \times(L P \times H S)^{595} \times(L P \times P A)^{16.7} \\
& \times(L P \times H T)^{-2.29} \times(S S \times H S)^{444} \\
& \times(S S \times P A)^{-6.27} \times(S S \times H T)^{1.48} \\
& \times(H S \times P A)^{0.8} \times(H S \times H T)^{-0.66} \\
& \times(P A \times H T)^{-0.53}
\end{aligned}
$$

Continuous regression equation for angled measurements

$$
\begin{aligned}
R_{a} \text { Angled }= & 10^{651} \times L P^{214.6} \times S S^{62.2} \times H S^{379} \times P A^{-100.42} \\
& \times H T^{53.32} \times(L P \times S S)^{-8} \times(L P \times H S)^{101} \\
& \times(L P \times P A)^{-21.66} \times(L P \times H T)^{-12.23} \\
& \times(S S \times H S)^{11.4} \times(S S \times P A)^{-13.28} \\
& \times(S S \times H T)^{5.84} \times(H S \times P A)^{-34.49} \\
& \times(H S \times H T)^{6.01} \times(P A \times H T)^{-3.145}
\end{aligned}
$$

Continuous regression equation for perpendicular measurements

$$
\begin{aligned}
R_{a} \text { Perpendicual }= & 10^{1723} \times L P^{-264} \times S S^{-173} \times H S^{781} \\
& \times P A^{-57.72} \times H T^{23.1} \times(L P \times S S)^{73} \\
& \times(L P \times H S)^{-41} \times(L P \times P A)^{1} \\
& \times(L P \times H T)^{-5.9} \times(S S \times H S)^{-24} \\
& \times(S S \times P A)^{-11.32} \times(S S \times H T)^{2.45} \\
& \times(H S \times P A)^{-14.4} \times(H S \times H T)^{2.32} \\
& \times(P A \times H T)^{-1.66}
\end{aligned}
$$

Open Access This article is licensed under a Creative Commons Attribution 4.0 International License, which permits use, sharing, adaptation, distribution and reproduction in any medium or format, as long as you give appropriate credit to the original author(s) and the source, provide a link to the Creative Commons licence, and indicate if changes were made. The images or other third party material in this article are included in the article's Creative Commons licence, unless indicated otherwise in a credit line to the material. If material is not included in the article's Creative Commons licence and your intended use is not permitted by statutory regulation or exceeds the permitted use, you will need to obtain permission directly from the copyright holder. To view a copy of this licence, visit http://creativecommons.org/licenses/by/4.0/.

\section{References}

1. Nikam SH, Jain NK, Sawant MS (2020) Optimization of parameters of micro-plasma transferred arc additive manufacturing process using real coded genetic algorithm. Int J Adv Manuf Technol 106(3-4):1239-1252

2. Gibson I et al (2020) Additive manufacturing technologies, Third edn. Springer, Berlin

3. Ning J, Praniewicz M, Wang W, Dobbs JR, Liang SY (2020) Analytical modeling of part distortion in metal additive manufacturing. Int J Adv Manuf Technol 107(1):49-57

4. Mahdavi M, et al. (2020) Prediction of the deformation behavior of a selective laser-melted Ti-6Al-4V alloy as a function of process parameters. Int J Adv Manuf Technol. 1-8

5. Delfs P, Tows M, Schmid HJ (2016) Optimized build orientation of additive manufactured parts for improved surface quality and build time. Addit Manuf 12:314-320

6. Chen Z, et al. (2018) Surface roughness of selective laser melted Ti6Al-4V alloy components. Additive Manufacturing 21:91-103

7. Sanaei N, Fatemi A, Phan N (2019) Defect characteristics and analysis of their variability in metal L-PBF additive manufacturing. Mater Des 182:108091

8. Yadroitsev I, Smurov I (2011) Surface morphology in selective laser melting of metal powders. Phys Procedia 12:264-270

9. Khorasani AM et al (2019) Modelling of laser powder bed fusion process and analysing the effective parameters on surface characteristics of Ti-6Al-4V. Int J Mech Sci 168:105299

10. Vayssette B, Saintier N, Brugger C, Elmay M, Pessard E (2018) Surface roughness of Ti-6Al-4V parts obtained by SLM and EBM: effect on the high cycle fatigue life. Proc Eng 213:89-97

11. Torres Y, et al. (2018) Surface modification of Ti-6Al-4V alloys manufactured by selective laser melting: Microstructural and tribomechanical characterization. Surf Coat Technol 348:31-40

12. Luis Perez CJ, Vivancos J, Sebastián MA (2001) Surface roughness analysis in layered forming processes. Precis Eng 25(1):1-12 
13. Gusarov AV, Kovalev EP (2009) Model of thermal conductivity in powder beds. Phys Rev B 80(2):024202

14. Strano G, Hao L, Everson RM, Evans KE (2013) Surface roughness analysis, modelling and prediction in selective laser melting. J Mater Process Technol 213(4):589-597

15. Pyka G, Kerckhofs G, Papantoniou I, Speirs M, Schrooten J, Wevers M (2013) Surface roughness and morphology customization of additive manufactured open porous Ti6Al4V structures. Materials 6(10):4737-4757

16. Tascioglu E, Karabulut Y, Kaynak Y (2020) Influence of heat treatment temperature on the microstructural, mechanical, and wear behavior of 316L stainless steel fabricated by laser powder bed additive manufacturing. Int J Adv Manuf Technol p. 1-10

17. Tascioglu E, Karabulut Y, Kaynak Y (2020) Correction to: Influence of heat treatment temperature on the microstructural, mechanical, and wear behavior of $316 \mathrm{~L}$ stainless steel fabricated by laser powder bed additive manufacturing. Int J Adv Manuf Technol, p. 1-10

18. Khorasani AM, Gibson I, Goldberg M, Littlefair G (2016) A survey on mechanisms and critical parameters on solidification of selective laser melting during fabrication of Ti-6Al-4V prosthetic acetabular cup. Mater Des 103:348-355

19. Khorasani A, Gibson I, Goldberg M, Littlefair G (2017) Production of Ti-6Al-4V acetabular shell using selective laser melting: possible limitations in fabrication. Rapid Prototyp J 23(1):110-121

20. Khorasani AM, Gibson I, Goldberg M, Masoud Movahedi M, Littlefair G (2017) Thermal stress flow analysis in fabrication of acetabular shells using SLM. KnE Eng 2(2):297-307

21. Welsch G, Boyer R, Collings E (1993) Materials properties handbook: titanium alloys. ASM International

22. Box G (1988) Signal-to-noise ratios, performance criteria, and transformations. Technometrics 30(1):1-17

23. Holman JP (1986) Heat transfer. Vol. 9. McGraw-hill, New York

24. Berthier J (2012) Micro-drops and digital microfluidics. William Andrew

25. Mills KC (2002) Recommended values of thermophysical properties for selected commercial alloys. Woodhead Publishing

26. Li R, Liu J, Shi Y, Wang L, Jiang W (2012) Balling behavior of stainless steel and nickel powder during selective laser melting process. Int J Adv Manuf Technol 59(9-12):1025-1035

27. Mahamood RM, Akinlabi ET (2017) Scanning speed and powder flow rate influence on the properties of laser metal deposition of titanium alloy. Int J Adv Manuf Technol 91(5-8):2419-2426

28. Aune R, Battezzati L, Brooks R, Egry I, Fecht HJ, Garandet JP, Mills KC, Passerone A, Quested PN, Ricci E, Schneider S, Seetharaman S, Wunderlich RK, Vinet B (2005) Surface tension and viscosity of industrial alloys from parabolic flight experiments - results of the ThermoLab project. Microgravity-Sci Technol 16(1-4):11-14

29. Wunderlich RK (2008) Surface tension and viscosity of industrial Ti-alloys measured by the oscillating drop method on board parabolic flights. High Temp Mater Process 27(6):401-412

30. Malkin AY, Isayev AI (2017) Rheology: concepts, methods, and applications. Elsevier
31. Weiland RH, Davis SH (1981) Moving contact lines and rivulet instabilities. Part 2. Long waves on flat rivulets. J Fluid Mech 107:261-280

32. Davis SH (1980) Moving contact lines and rivulet instabilities. Part 1. The static rivulet. J Fluid Mech 98(2):225-242

33. Schiaffino S, Sonin AA (1997) Formation and stability of liquid and molten beads on a solid surface. J Fluid Mech 343:95-110

34. Tian Y, Tomus D, Rometsch P, Wu X (2017) Influences of processing parameters on surface roughness of Hastelloy $\mathrm{X}$ produced by selective laser melting. Addit Manuf 13:103-112

35. Khorasani AM, Gibson I, Ghaderi AR (2018) Rheological characterization of process parameters influence on surface quality of Ti$6 \mathrm{Al}-4 \mathrm{~V}$ parts manufactured by selective laser melting. Int $\mathrm{J}$ Adv Manuf Technol 97(9-12):3761-3775

36. Khorasani AM, et al. (2018) Investigation on the effect of heat treatment and process parameters on the tensile behaviour of SLM Ti-6Al-4V parts. Int J Adv Manuf Technol 101(9-12)31833197

37. Averyanova M, Cicala E, Bertrand P, Grevey D (2012) Experimental design approach to optimize selective laser melting of martensitic 17-4 PH powder: part I-single laser tracks and first layer. Rapid Prototyp J 18(1):28-37

38. Mishra AK, Aggarwal A, Kumar A, Sinha N (2018) Identification of a suitable volumetric heat source for modelling of selective laser melting of Ti6Al4V powder using numerical and experimental validation approach. Int J Adv Manuf Technol 99(9-12):2257-2270

39. Sieniawski J, et al. (2013) Microstructure and mechanical properties of high strength two-phase titanium alloys. Titanium AlloysAdvances in Properties Control, 69-80

40. Jovanović $\mathrm{M}$ et al (2006) The effect of annealing temperatures and cooling rates on microstructure and mechanical properties of investment cast Ti-6Al-4V alloy. Mater Des 27(3):192-199

41. Beaucamp AT et al (2015) Finishing of additively manufactured titanium alloy by shape adaptive grinding (SAG). Surf Topogr: Metrol Properties 3(2):024001

42. Khorasani AM, et al. (2016) Production of Ti-6Al-4V acetabular shell using selective laser melting: possible limitations in fabrication. Rapid Prototyp J. https://doi.org/10.1108/RPJ-11-2015-0159

43. Gorny B, Niendorf T, Lackmann J, Thoene M, Troester T, Maier HJ (2011) In situ characterization of the deformation and failure behavior of non-stochastic porous structures processed by selective laser melting. Mater Sci Eng A 528(27):7962-7967

44. Qiu C, Panwisawas C, Ward M, Basoalto H, Brooks J, Attallah M (2015) On the role of melt flow into the surface structure and porosity development during selective laser melting. Acta Mater 96: 72-79

45. Baufeld B, Van der Biest O, Gault R (2010) Additive manufacturing of Ti-6Al-4V components by shaped metal deposition: microstructure and mechanical properties. Mater Des 31:S106-S111

Publisher's note Springer Nature remains neutral with regard to jurisdictional claims in published maps and institutional affiliations. 